\title{
Numerical Study of Heat Transfer of Water Flow through Pipe with Property Variations
}

\author{
By Amjad Ali Pasha* \\ A. Mushtaq ${ }^{\dagger}$ \\ Khalid A. Juhany
}

\begin{abstract}
Microchannels, with their small size and high heat dissipation capacity, play an important role in electronic devices. The present study deals with steady, laminar, incompressible, single phase liquid water flow, with constant wall heat flux, through a micro-pipe. Numerical simulations are performed for two-dimensional axisymmetric pipe for developing flow at the entrance. The effect of constant and variable thermophysical properties, at the inlet boundary, on heat transfer and hydrodynamic characteristics is examined with variations of radius, inlet velocities, and constant wall heat flux. It is observed that the Nusselt number increases with an increase in radii and inlet velocities and depicts higher values with variable property flows as compared to constant property flows.
\end{abstract}

Keywords: Heat flux, Mean temperature, Micropipe, Nusselt number, Thermal conductivity, Viscosity.

\section{Introduction}

Liquid flow through micro ducts is used to dissipate heat in miniature engineering systems, which is of paramount importance for their performance. Fluid flow, through conventional macro size ducts, has been extensively studied to develop the well-established analytical relations of heat transfer (Weilin et al., 2000; Sobhan et al., 2001; Morini, 2004; Hetsroni et al., 2005a; Mahmoud and Karayiannis, 2013). Unfortunately, there exist many discrepancies between the mechanism of fluid flow and heat transfer in macro ducts and micro ducts. This opens a broad door to unveil the flow physics in the area of micro-convection heat transfer.

The first micro channel experimental studies performed by Tuckerman and Pease (1981), demonstrated that greater heat transfer rate could be achieved with smaller diameters. Subsequently, several investigations have been conducted over the past years to practically analyze the flow through micro channels (Kohl et al., 2005; Liu and Garimella, 2007; Dirker et al., 2014; Asadi et al., 2014). However, experimental measurements for micro channel pipes face a major challenge till date. As an alternative, numerical simulations have been employed by researchers, to overcome this limitation (Molho et al., 2005;

\footnotetext{
* Assistant Professor, King Abdul Aziz University, Saudi Arabia.

${ }^{\dagger}$ Graduate Student, King Abdul Aziz University, Saudi Arabia.

${ }^{\ddagger}$ Chairman/Assistant Professor, King Abdul Aziz University, Saudi Arabia.
} 
Hetsroni et al., 2005b; Gulhane and Mahulikar, 2010; Gulhane and Mahulikar, 2011; Dixit and Ghosh, 2015).

Generally, constant properties (CP) are assumed in fluid flow and heat transfer analytical calculations for duct flows. The effect of fluid property variations with temperature such as density $\rho(T)$, thermal conductivity $k(T)$, specific heat at constant pressure $\mathrm{C}_{\mathrm{P}}(\mathrm{T})$ and viscosity $\mu(\mathrm{T})$, are generally neglected, that account for large temperature differences when compared with constant properties and around 30\% deviation in Nusselt number $(\mathrm{Nu})$ (Herwig and Mahulikar, 2006; Ozalp, 2010). Experimental evidence with a comprehensive review of the literature were provided by researchers showing the discrepancies present in literature for frictional factor and pressure drop for flows through micro channels (Muzychka and Yovanovich, 1998; Steinke and Kandlikar, 2005).

Our main objective is to investigate the effects of temperature variation of thermo physical properties like $\rho(T), k(T), C_{P}(T)$ and $\mu(T)$, on heat transfer and hydrodynamic characteristics i.e. Nusselt number $(\mathrm{Nu})$, pressure drop $\Delta \mathrm{p}$, Darcy friction factor $f_{D}$ and skin friction coefficient $C_{f}$ for developing water flow through the micro pipe. Also, the effect of variation in diameter, inlet velocities, and constant wall heat flux is studied on these characteristics.

The paper is organized as follows. First, the simulation methodology is discussed. In this section, governing equations, geometry details, grid convergence study, numerical method, and formulas are discussed. Next, the computed velocity and temperature profiles are discussed for constant and variable properties (CP and VP) respectively and compared to analytical conventional profiles of pipe flow. Next, the isolation and combined effects of variable properties (VP) on heat transfer and fluid flow characteristics are studied and compared to constant property (CP) numerical results. Next, the effect of different radii, inlet velocities and wall heat wall fluxes on these characteristics is studied for constant and variable properties (CP and VP). Finally, the conclusions are discussed.

\section{Simulation Methodology}

\section{Governing Equations}

The conservation equations of mass, momentum, and energy used in numerical simulations are described below. The single-phase liquid flow is assumed to be laminar, steady, and incompressible (Rohsenow et al., 1998).

Continuity equation:

$\frac{1}{r} \frac{\partial\left(r u_{r}\right)}{\partial r}+\frac{\partial u_{z}}{\partial z}=0$

r-component momentum equation:

$\rho\left(u_{r} \frac{\partial u_{r}}{\partial r}+u_{z} \frac{\partial u_{r}}{\partial z}\right)=-\frac{\partial p}{\partial r}+\mu\left[\frac{l}{r} \frac{\partial}{\partial r}\left(r \frac{\partial u_{r}}{\partial r}\right)-\frac{u_{r}}{r^{2}}+\frac{\partial^{2} u_{r}}{\partial z^{2}}\right]$ 
Z-component momentum equation:

$\rho\left(u_{r} \frac{\partial u_{z}}{\partial r}+u_{z} \frac{\partial u_{z}}{\partial z}\right)=-\frac{\partial p}{\partial z}+\mu\left[\frac{1}{r} \frac{\partial}{\partial r}\left(r \frac{\partial u_{z}}{\partial r}\right)+\frac{\partial^{2} u_{z}}{\partial z^{2}}\right]$

Energy equation:

$$
\rho C_{p}\left(u_{r} \frac{\partial T}{\partial r}+u_{z} \frac{\partial T}{\partial z}\right)=k\left[\frac{l}{r} \frac{\partial}{\partial r}\left(r \frac{\partial T}{\partial r}\right)+\frac{\partial^{2} T}{\partial z^{2}}\right]+2 \mu l\left(\frac{\partial u_{r}}{\partial r}\right)^{2}+\left(\frac{\partial u}{\partial z}\right)^{2}+\mu\left\{\left(\frac{\partial u}{\partial r}+\frac{\partial u_{r}}{\partial z}\right)^{2}\right\}
$$

Here, $r$ and $z$ are radial and axial coordinates, $\mathrm{u}_{\mathrm{r}}$ is the velocity component in the radial direction and $\mathrm{u}_{\mathrm{z}}$ is the velocity component in the axial direction as shown in Figure 1, and $\mathrm{p}$ is the pressure. In incompressible flow, the density $\rho$, viscosity $\mu$, thermal conductivity $\mathrm{k}$, specific heat capacity at constant pressure $\mathrm{C}_{\mathrm{p}}$ are assumed as constants, which is a poor assumption for micro channels. A more accurate approach to solve these equations would be to assume the dependence of these properties on temperature. In Eq. 1, the left-hand side is the total mass flux passing in axial and radial directions through the control surface per unit volume. The left-hand terms in Eq. 2 and 3 represent the rate of momentum transfer by convection per unit volume in axial and radial directions. The first and second terms on right-hand side represent the pressure and viscous forces acting on control surface per unit volume in axial and radial directions. The gravitational force is neglected. The left-hand side of Eq. 4, is the total energy lost by convection while the first term on the right-hand side is the amount of heat transfer by conduction per unit volume. It is given by Fourier's law, $\mathrm{q}=-\mathrm{k} \nabla \mathrm{T}$. Where $\mathrm{k}$ is the thermal conductivity and $\mathrm{T}$ is the temperature. The second term represents the work done by shear forces.

\section{Numerical Details}

Figure 1. The Two-dimensional Axisymmetric Geometry of the Micro Pipe showing Temperature and Velocity Profiles with Constant Heat Flux Boundary Condition on the Wall

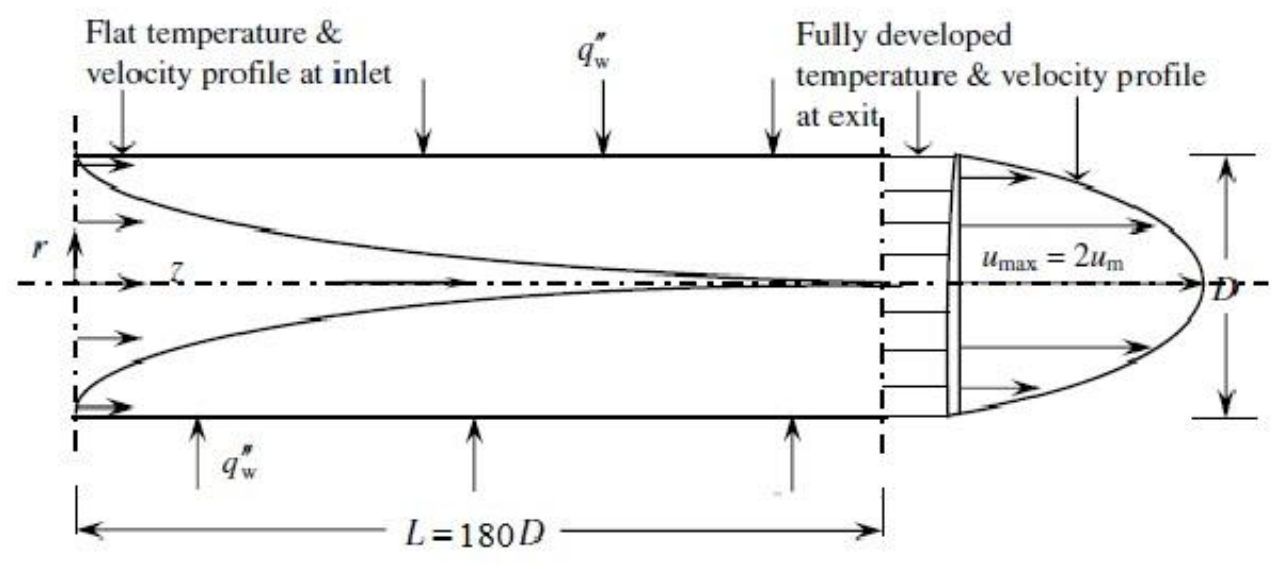

Two-dimensional axisymmetric geometry is generated using Pointwise V17.2 R2 package. The domain extends to a length of $\mathrm{L}=0.018 \mathrm{~m}$ in the axial 
direction and to a diameter of $\mathrm{D}=10 \times 10^{-5} \mathrm{~m}$ in the radial direction as shown in Figure 1. Based on grid convergence study (see Figure 2), a grid size of $400 \mathrm{x}$ 100 in axial and radial directions is used in the numerical simulations. The grid is clustered at an inlet and near the wall. A first cell distance of $5 \times 10^{-6} \mathrm{~m}$ is taken to capture the velocity and temperature gradients.

Figure 2. Variation of Nusselt Number $N u$, with Different Grids for Water Flow, through the Micro Pipe of Radius $R=5 \times 10^{-5} \mathrm{~m}$, Inlet Velocity $u_{\text {in }}=3 \mathrm{~m} / \mathrm{s}$, and Constant Wall Heat flux, $q_{w}=100 \mathrm{~W} / \mathrm{cm}^{2}$

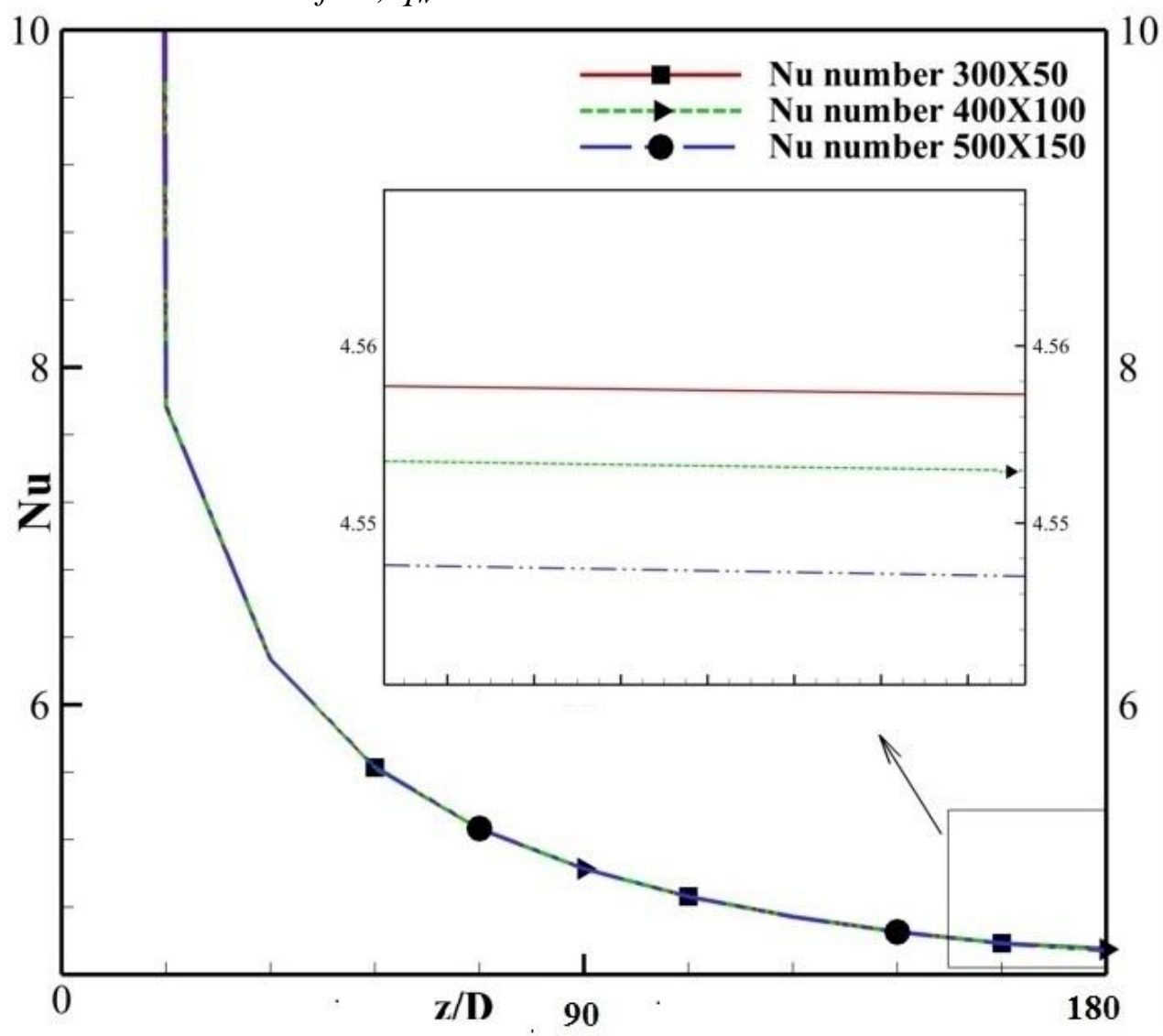

An in-house code is used to carry out the numerical simulations. The postprocessing is done using Tecplot 360 package. The governing equations are discretized using second-order finite volume technique. The SIMPLE scheme is used to couple the velocity and pressure variables (Patankar, 1980). The implicit method is used to reach the steady-state solutions. The no-slip velocity and uniformly distributed constant heat flux boundary condition are used on the wall. The inlet boundary conditions of velocity $u_{\text {in }}=3 \mathrm{~m} / \mathrm{s}$, temperature $T_{\text {in }}$ $=273.65 \mathrm{~K}$ are taken. At the outlet pressure $\mathrm{p}_{\text {out }}=1.01325 \times 10^{5} \mathrm{~Pa}$, is assumed. At center line, an axisymmetric boundary condition i.e. gradients in the axial direction, $\partial(\mathrm{p}) / \partial \mathrm{z}, \partial(\mathrm{T}) / \partial \mathrm{z}$ and $\partial(\rho) / \partial \mathrm{z}$ are assumed to be zero. 


\section{Thermophysical Properties}

The thermophysical properties of water, i.e. $\rho(T), k(T), C_{P}(T)$ and $\mu(T)$ are assumed to depend only on temperature. The polynomial functions of second and third order are used to curve fit the data (see Figure 3 ) in the temperature range of 278.15 to $372 \mathrm{~K}$ at 1 bar pressure (Bergman and Incropera, 2011).

$\rho(\mathrm{T})=765.33+1.8142(\mathrm{~T})-0.0035(\mathrm{~T})^{2}$

$\mathrm{C}_{\mathrm{P}}(\mathrm{T})=1.095 \mathrm{e}^{4}-59.27(\mathrm{~T})+0.171(\mathrm{~T})^{2}-0.0001623(\mathrm{~T})^{3}$

$\mathrm{k}(\mathrm{T})=-0.5752+6.3967 \times 10^{-3}(\mathrm{~T})-8.151 \times 10^{-6}(\mathrm{~T})^{2}$

$\mu(\mathrm{T})=9.67 \times 10^{-2}-8.207 \times 10^{-4}(\mathrm{~T})+2.344 \times 10^{-6}(\mathrm{~T})^{2}-2.244 \times 10^{-9}(\mathrm{~T})^{3}$

Figure 3 shows that as temperature increases, $k(T)$ increases and both $\rho(T)$ and $\mu(\mathrm{T})$ decreases. $\mathrm{C}_{\mathrm{P}}(\mathrm{T})$ first decreases with increase in temperature and then increases. These thermo physical variable properties (VP) used in our numerical simulations differ from formulations used in Ref. (Gulhane and Mahulikar, 2011). Also, the constant properties (CP) in our simulations are calculated at the fluid mean temperature in contrary to the simulations by Gulhane and Mahulikar (2011) where CP calculations are performed at inlet temperature.

Figure 3. Comparison of Polynomial Function Curves to the Available Data (Bergman and Incropera, 2011) for Variation of Thermophysical Properties with Temperature

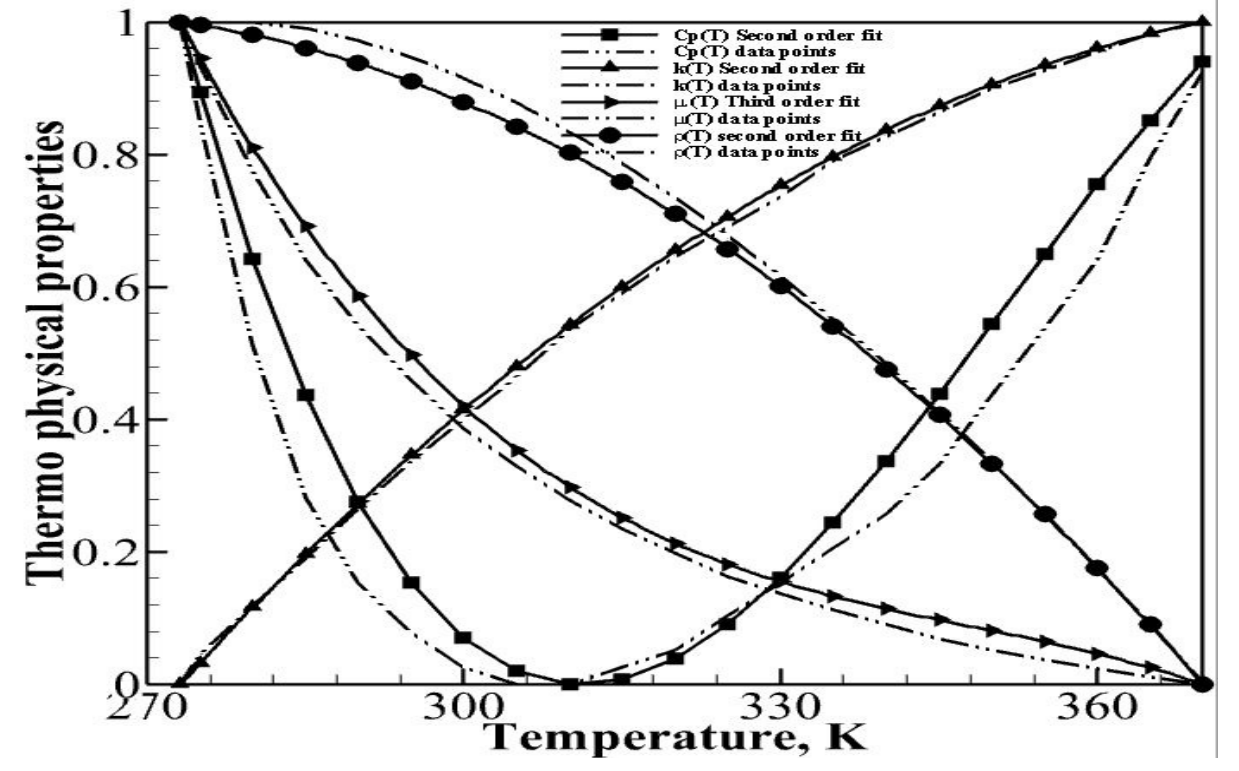

Formulas

A numerical sample calculation is explained as follows. The mass flow rate of water flow through a micro pipe of radius $\mathrm{R}=5 \times 10^{-5} \mathrm{~m}$ with an inlet velocity of $u_{i n}=3 \mathrm{~m} / \mathrm{s}$ is given as $\mathrm{m}=\rho \mathrm{Au}_{\text {in }}$. Here, $\mathrm{A}=\pi \mathrm{R}^{2} / 2$ is cross sectional 
area of pipe. The local mean bulk temperature at any location along the z-axis, $\mathrm{T}_{\mathrm{m}(\mathrm{z})}$ and exit temperature $\mathrm{T}_{\mathrm{e}}$ is calculated by

$$
T m(z)=\frac{2}{u_{m} R^{2}} \int_{0}^{R} T(r) u(r) r d r ; \quad T_{e}=T_{i n}+\frac{q_{w} A_{w}}{m C_{p}}
$$

Here, $r$ is the radius of pipe, $T_{\text {in }}$ is inlet temperature, $\mathrm{q}_{\mathrm{w}}$ is constant wall heat flux and $T_{e}$ is exit temperature. The constant properties (CP), density $\rho$, viscosity $\mu$, thermal conductivity $\mathrm{k}$ and specific heat $\mathrm{C}_{\mathrm{p}}$ are calculated at bulk fluid temperature i.e. $T_{b}=\left(T_{\text {in }}+T_{e}\right) / 2$ is $289.64 \mathrm{~K}$, where $T_{\text {in }}$ is taken as 273.65 $\mathrm{K}$. The fluid properties at $\mathrm{T}_{\mathrm{b}}$ are $\rho=998.66\left(\mathrm{~kg} / \mathrm{m}^{3}\right), \mathrm{C}_{\mathrm{p}}=4184(\mathrm{~J} / \mathrm{kg}-\mathrm{K}), \mathrm{k}=$ $0.5926(\mathrm{~W} / \mathrm{m}-\mathrm{K})$, and $\mu=0.00108353(\mathrm{~kg} / \mathrm{m}-\mathrm{s})$. The Prandtl number, Pr $=7.65$, therefore the momentum transport by diffusion in velocity boundary layer is higher than energy transport by diffusion in the thermal boundary layer. The Reynolds number, Re based on the hydraulic diameter $\mathrm{D}=2 \mathrm{R}$, is calculated as

$$
R e=\frac{\rho u_{i n} D}{\mu}=276.501
$$

Since, $\operatorname{Re} \leq 2300$, the flow is assumed to be laminar. The hydro dynamically developed flow length, $L_{h}$ and thermally developed flow length, $L_{t}$ is calculated by

$L_{h}=0.05 \operatorname{Re} D=0.00138$

$L_{t}=L_{h} \operatorname{Pr}=0.0105$

The $L_{h}$ is calculated, at the location when the velocity profile does not change in the axial direction i.e. $\partial \mathrm{u} / \partial \mathrm{z}=0$. The $L_{t}$ is calculated where the temperature profile is only a function of radial direction. The local surface temperature of the pipe at along $\mathrm{z}$ is calculated as

$T_{w(z)}=\left(q_{w} / h\right) T_{m(z)}$

The Nusselt number $\mathrm{Nu}$ is calculated as the ratio of convective to conductive heat transfer normal to the boundary. The Nusselt number for constant properties $\left(\mathrm{Nu}_{\mathrm{CP}}\right)$ and variable properties $\left(\mathrm{Nu}_{\mathrm{VP}}\right)$ is calculated numerically for fully developed flow as follows:

$$
\begin{aligned}
& N u_{C P}=\frac{h D}{k}=\frac{q_{w} D}{k\left(T_{w}-T_{m}\right)_{C P}}=4.53 \\
& N u_{V P}=\frac{h D}{k(T)}=\frac{q_{w} D}{k_{V P}\left(T_{w}-T_{m}\right)_{V P}}=5.25
\end{aligned}
$$

Here, $k(T)$ has direct effect on $\mathrm{Nu}_{\mathrm{vp}}$, whereas $\rho(\mathrm{T})$ and $\mu(\mathrm{T})$ and $\mathrm{C}_{\mathrm{P}}(\mathrm{T})$ effects the wall and mean temperature $\left(\mathrm{T}_{\mathrm{w}}\right.$ and $\mathrm{T}_{\mathrm{m}}$ respectively), and consequently has an indirect effect on Nusselt number, $\mathrm{Nu}$. 
The skin friction coefficient for constant property flow $C_{f_{C P}}$ and variable property flow $C_{f_{V P}}$ are calculated as follows.

$$
\begin{aligned}
C_{f_{C P}}= & \frac{\mu\left(\frac{\partial u}{\partial r}\right)_{C P}}{0.5 \rho_{i n} u_{i n}^{2}} \\
C_{f_{V P}}= & \frac{\mu(T)\left(\frac{\partial u}{\partial r}\right)_{V P}}{0.5 \rho_{i n} u_{i n}^{2}}
\end{aligned}
$$

The Darcy friction factor $f_{D}$ is defined in terms of non-dimensional mean pressure gradient $(d p / d z)_{m}$ along the length of the channel by,

$$
f_{D}=\frac{D\left(\frac{\partial p}{\partial z}\right)_{m}}{0.5 \rho_{m} u^{2}}
$$

Where, $\rho_{m}$ is the mean density. The mean pressure drop along the length of the channel L is defined in terms of inlet pressure $P_{\text {in }}$ and outlet pressure $P_{\text {out }}$.

$$
\frac{\Delta p}{L}=\frac{P_{\text {in }}-P_{\text {out }}}{L}
$$

\section{Test Cases}

In this work three case studies are simulated as given in Tables 1-3. These cases are simulated for both CP and VP to study their effect on flow and heat transfer rates for developing flow in micro pipe. In case-1 study, radius of pipe is varied keeping all the other properties constant. Similarly, in Cases 2 and 3, the inlet velocities and wall heat flux are varied.

Table 1. Variation of Radius $(m)$

\begin{tabular}{ll}
\hline Case-1 & \\
\hline \hline Radius (m) & $5 \times 10^{-5}, 1.5 \times 10^{-4}, 2 \times 10^{-4}$ \\
Inlet temperature & $273.65 \mathrm{~K}$ \\
Inlet velocity & $3 \mathrm{~m} / \mathrm{s}$ \\
Wall heat flux & $100 \mathrm{~W} / \mathrm{cm}^{2}$ \\
Outlet pressure & $1.01325 \times 10^{5} \mathrm{~Pa}$ \\
\hline
\end{tabular}


Table 2. Variation of Inlet Velocity $(\mathrm{m} / \mathrm{s})$

\begin{tabular}{ll}
\hline Case-2 & \\
\hline \hline Radius & $5 \times 10^{-5} \mathrm{~m}$ \\
Inlet temperature & $273.65 \mathrm{~K}$ \\
Inlet velocity $(\mathrm{m} / \mathrm{s})$ & $3,7.5,15$ \\
Wall heat flux & $100 \mathrm{~W} / \mathrm{cm}^{2}$ \\
Outlet pressure & $1.01325 \times 10^{5} \mathrm{~Pa}$ \\
\hline
\end{tabular}

Table 3. Variation of Wall Heat Flux $\left(W / \mathrm{cm}^{2}\right)$

\begin{tabular}{ll}
\hline Case-3 & \\
\hline \hline Radius & $5 \times 10^{-5} \mathrm{~m}$ \\
Inlet temperature & $273.65 \mathrm{~K}$ \\
Inlet velocity & $3 \mathrm{~m} / \mathrm{s}$ \\
Wall heat flux, $\mathrm{W} / \mathrm{cm}^{2}$ & $50,100,140$ \\
Outlet pressure & $1.01325 \times 10^{5} \mathrm{~Pa}$ \\
\hline
\end{tabular}

\section{Results and Discussion}

\section{Velocity and Temperature Profiles}

In this section, we numerically study the effect of variable properties (VP) $\mathrm{C}_{\mathrm{p}}(\mathrm{T}), \rho(\mathrm{T}), \mathrm{k}(\mathrm{T}), \mu(\mathrm{T})$ in isolation and combination to investigate their effect on heat transfer rates. A pipe radius of $5 \times 10^{-5} \mathrm{~m}$ at inlet velocity and temperature 3 $\mathrm{m} / \mathrm{s}$ and $273.65 \mathrm{~K}$ at uniform wall heat wall flux of $100 \mathrm{~W} / \mathrm{cm}^{2}$ is taken in the simulations. An outlet pressure of $1.01325 \times 10^{5} \mathrm{~Pa}$ is assigned at pipe exit. The results are compared to constant properties (CP) and theoretical data of conventional pipe flows. At the inlet, the uniform velocity profile is assumed. As the fluid flows along the length of the pipe, velocity reaches its maximum value at centre and attains a parabolic profile. At this point, the flow is said to be hydro dynamically fully developed. Beyond this point, the velocity does not change along $\mathrm{z}$-axis i.e. $\partial \mathrm{u} / \partial \mathrm{z}=0$, remains constant throughout.

In the present calculations, it is observed that the flow is hydro dynamically developed at $\mathrm{z} / \mathrm{D}=20$ with a maximum centre velocity of $5.9934 \mathrm{~m} / \mathrm{s}$ for $\mathrm{CP}$ as shown in Figure 4. The flow develops later for VP near the pipe exit with a maximum velocity at centre line $=5.99447 \mathrm{~m} / \mathrm{s}$. Theoretically, for conventional pipes, the flow becomes fully developed at $\mathrm{u}_{\mathrm{r}}=2 \mathrm{u}_{\mathrm{m}}\left[1-(\mathrm{r} / \mathrm{R})^{2}\right]$ and its maximum value at centre of the pipe is given by $6 \mathrm{~m} / \mathrm{s}$ (Bergman and Incropera, 2011). This value is higher as compared to the flow through micro pipes for $\mathrm{CP}$ and VP. 
Figure 4. Velocity Profile for Developing Flow with $u_{\text {in }}=3 \mathrm{~m} / \mathrm{s}, R=5 \times 10^{-5} \mathrm{~m}$ and $q_{w}=100 \mathrm{~W} / \mathrm{cm}^{2}$ for CP and VP compared to Theory (Bergman and Incropera, 2011)

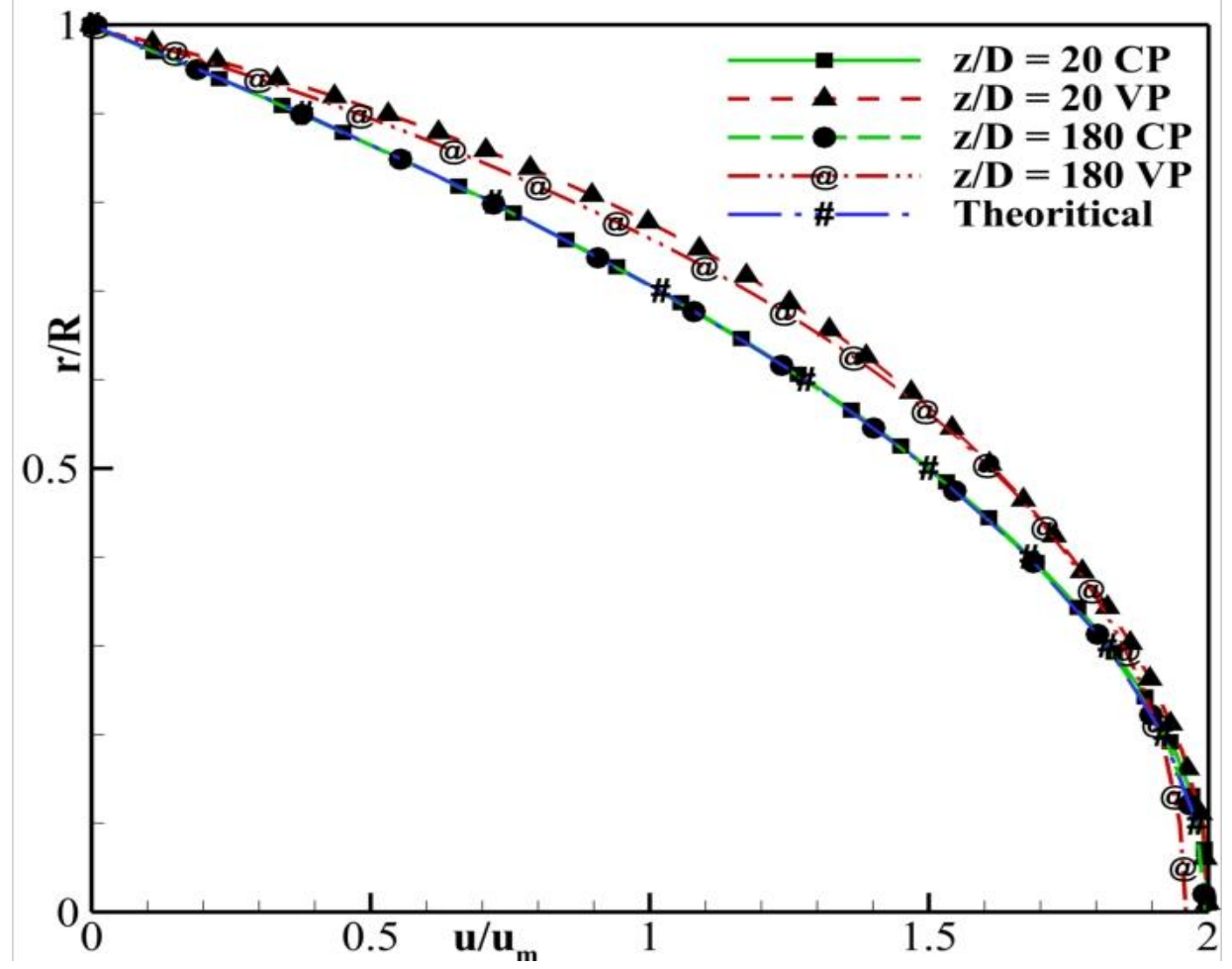

Figure 5. Variation of Radial Velocity in $\mathrm{m} / \mathrm{s}$, with $u_{\text {in }}=3 \mathrm{~m} / \mathrm{s}, R=5 \times 10^{-5} \mathrm{~m}$ and $q_{w}=100 \mathrm{~W} / \mathrm{cm}^{2}$ with Constant Property $(C P)$, Properties $C_{p}(T), \rho(T), k(T)$ and $\mu(T)$ in Isolation and their Combination (VP)

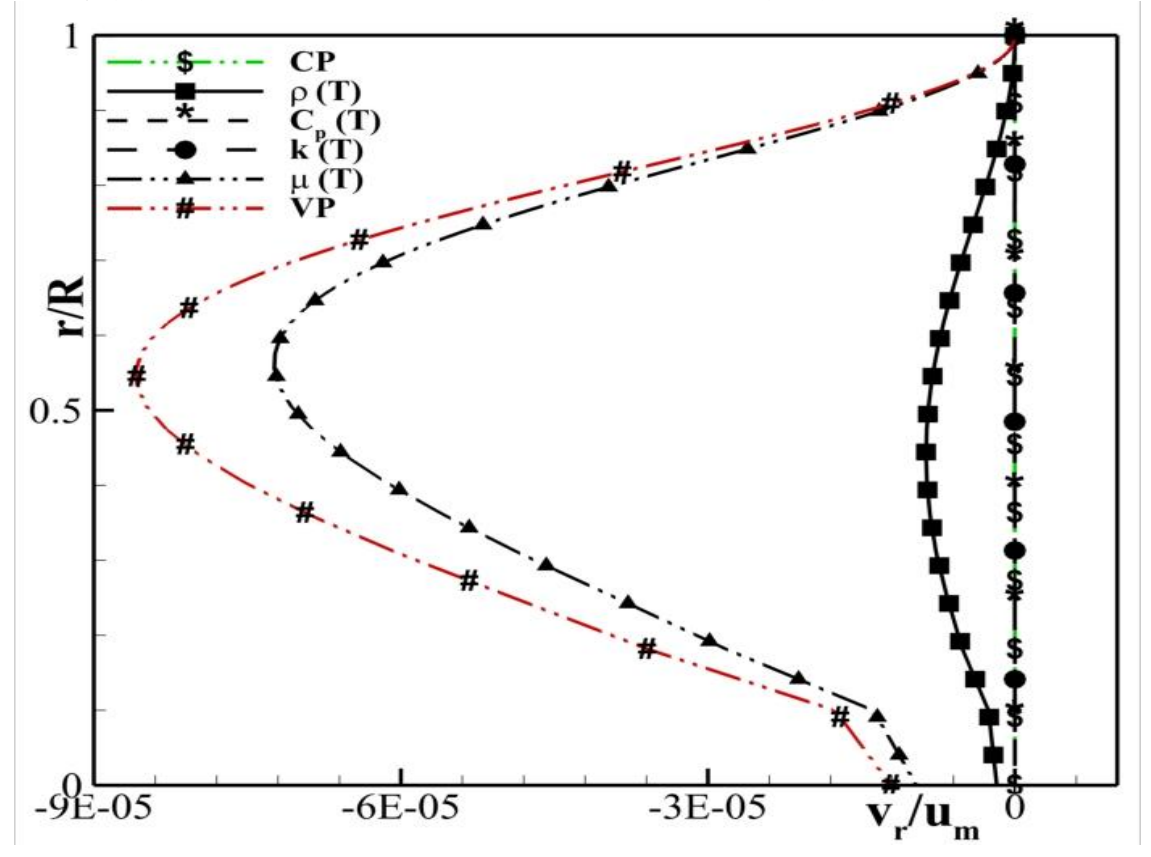


Figure 5 shows that the radial velocity is negligible for $\mathrm{CP}$ hence convection is zero in radial direction with $\mathrm{CP}$. There is a small magnitude of the radial velocity with VP indicating radial convection. The major effect is due to $\mu(\mathrm{T})$ and minor is due to $\rho(T)$. The $k(T)$ and $C_{p}(T)$ variations have a negligible effect on the radial velocity profile.

Figure 6. Temperature Profile for Developing Flow with $u_{\text {in }}=3 \mathrm{~m} / \mathrm{s}, R=5 \times 10^{-5}$ $m$ and $q_{w}=100 \mathrm{~W} / \mathrm{cm}^{2}$ for Constant Property $(C P)$ and Variable Property (VP) compared to Conventional Theory

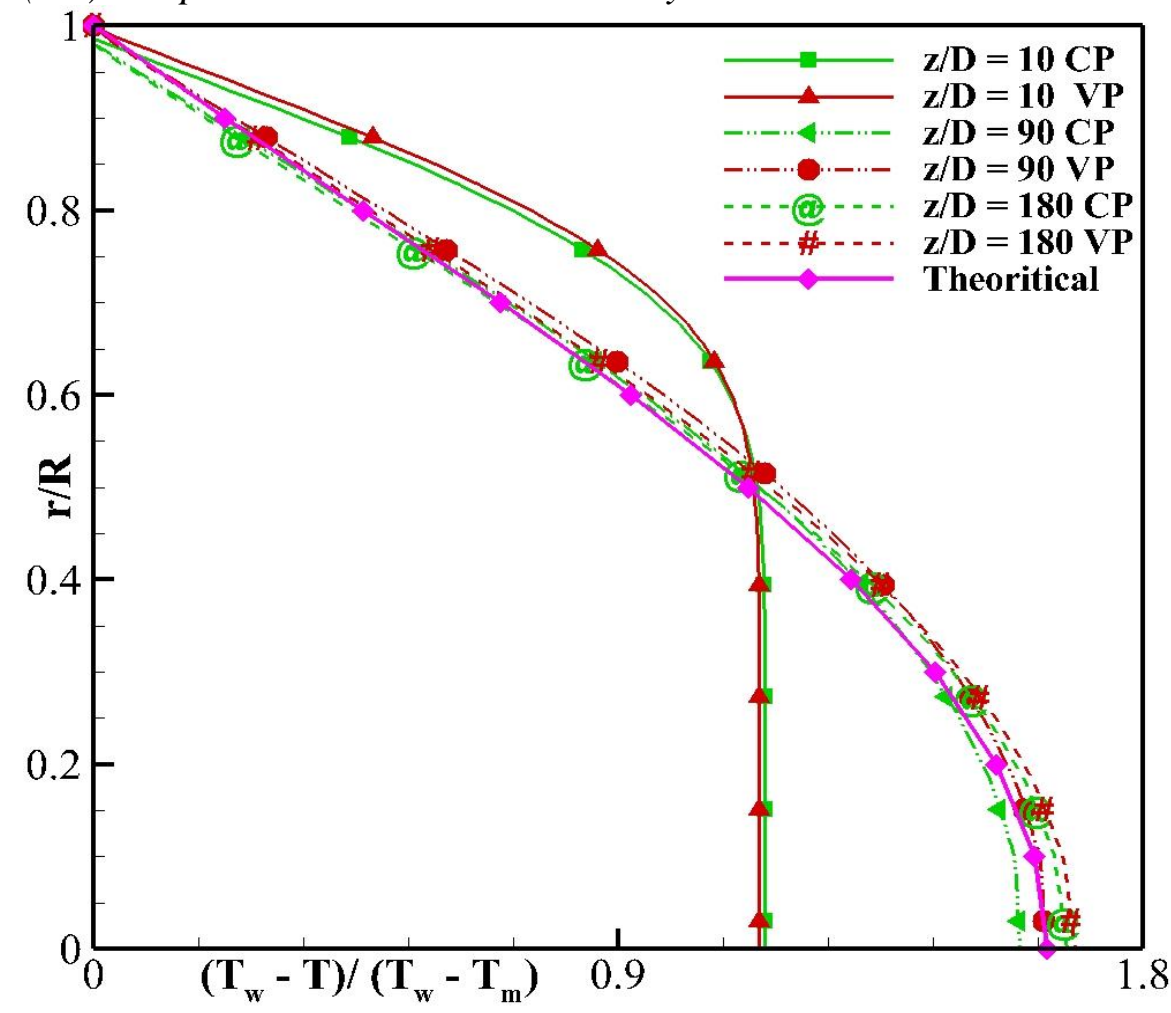

Uniform temperature profile is given at inlet with $T_{i n}=273.65 \mathrm{~K}$. As the liquid flows along the length of the pipe, the temperature rises due to constant heat flux of $\mathrm{q}_{\mathrm{w}}=100 \mathrm{~W} / \mathrm{cm}^{2}$ at the wall. When the temperature profile does not change after certain distance from entrance then it is said to be thermally fully developed flow. In our calculations, the flow is still developing for CP and VP as shown in Figure 6. The theoretical thermally fully developed flow for conventional pipes is given by

$$
\begin{aligned}
& T(r, x)=T_{w}(x)-\frac{2 u_{m} R^{2}}{\alpha} \frac{d T_{m}}{d x}\left[\left(\frac{3}{16}\right)+\frac{1}{16}\left(\frac{r}{R}\right)^{4}-\frac{1}{4}\left(\frac{r}{R}\right)^{2}\right] \\
& T_{m}(x)=T_{w}(x)-\frac{11 u_{m} R^{2}}{48 \alpha} \frac{d T_{m}}{d x}
\end{aligned}
$$

Here $\alpha=k /\left(\rho C_{p}\right)$. Since the Prandtl number is more than one for water, the velocity boundary layer develops faster as compared to thermal developing 
boundary layer for $\mathrm{CP}$ as shown in Figures 4 and 6. Note that both the $\mathrm{CP}$ and VP fluid flows show deviation from the calculated theoretical temperature at pipe exit in Figure 6.

Effects of Constant Properties and Temperature Variable Thermophysical Properties on Nusselt Number in Isolation and Combination

The thermo physical fluid properties such as $\rho(T), C_{p}(T), k(T)$ and $\mu(T)$ are dependent on temperature and their effect on heat transfer cannot be neglected. The individual and combined effects of these properties are analysed on mean $T_{m}$ and wall temperature $T_{w}$, and their temperature difference $\left(T_{w}-T_{m}\right)$, and are compared to the solution with constant properties (CP) in Figure 7. It is observed that the variation of $\mu(\mathrm{T})$ and $\mathrm{k}(\mathrm{T})$ has major influence on wall temperature and negligible effects are observed with variation of $\mathrm{C}_{\mathrm{p}}(\mathrm{T})$ and $\rho(\mathrm{T})$ as compared to CP. The combined effects of these properties (VP) predict lower values of $\mathrm{T}_{\mathrm{w}}$ as compared to $\mathrm{CP}$. The $\mathrm{CP}$ and $\mathrm{VP}$ solution for $\mathrm{T}_{\mathrm{m}}$ matches.

Figure 7. Water Flow through Pipe with $u_{\text {in }}=3 \mathrm{~m} / \mathrm{s}, R=5 \times 10^{-5} \mathrm{~m}$ and $q_{w}=100$ $W / \mathrm{cm}^{2}$ for Constant Properties CP, Variable Properties in Isolation and their Combination (VP) Depicting Variation of (a) Wall Temperature $T_{w}$ and Mean Temperature $T_{m}$ and $(b)$ Temperature Difference $\Delta T=\left(T_{w}-T_{m}\right)$
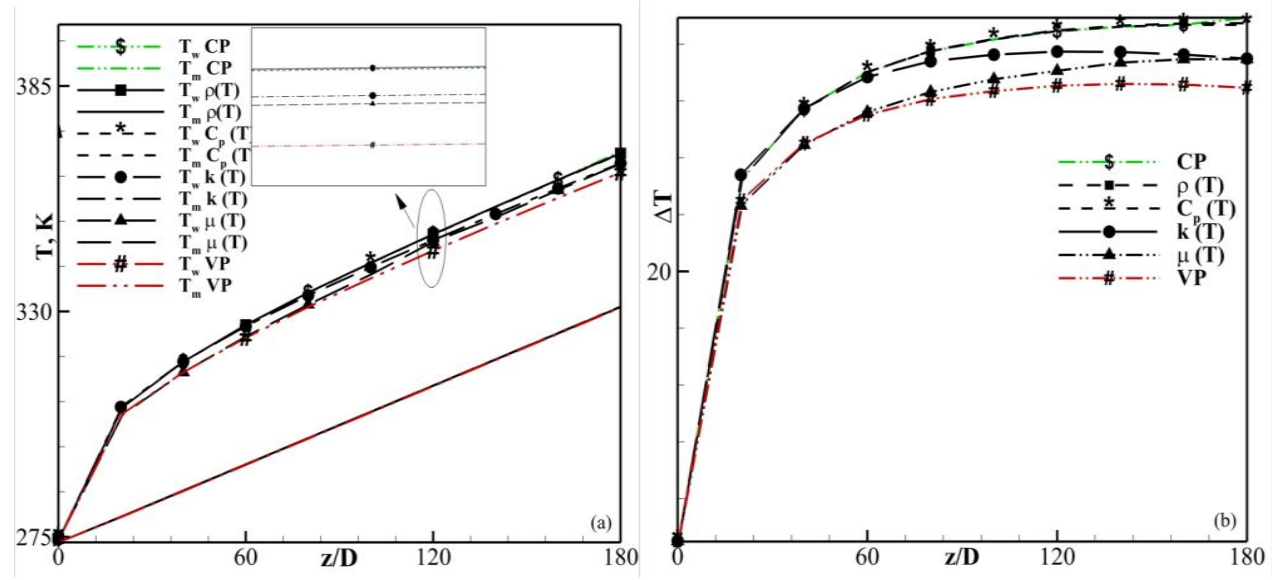

The overall effect of wall and mean temperatures on the Nusselt number, $\mathrm{Nu}$ is shown in Figure 8 for both CP and VP. The Nu depends on two parameters; $\mathrm{k}$ and temperature difference, $\Delta \mathrm{T}=\left(\mathrm{T}_{\mathrm{w}}-\mathrm{T}_{\mathrm{m}}\right)$ as given by Eqs 14. and 15 . Firstly, the constant heat addition from wall pipe increases temperature in axial direction of pipe. This increase in temperature, increases $\mathrm{k}(\mathrm{T})$ as shown in Figure 1. The effect of this increase in $\mathrm{k}(\mathrm{T})$, decreases the $\mathrm{Nu}_{\mathrm{VP}}$ as compared to $\mathrm{Nu}_{C P}$. Secondly, the overall effect of $\mathrm{C}_{\mathrm{p}}(\mathrm{T}), \rho(\mathrm{T}), \mathrm{k}(\mathrm{T})$ and $\mu(\mathrm{T})$ as compared to constant properties results in $\Delta \mathrm{T}_{\mathrm{CP}}>\Delta \mathrm{T}_{\mathrm{VP}}$, thereby resulting in decrease in $\mathrm{Nu}_{\mathrm{CP}}$ as compared to $\mathrm{Nu}_{\mathrm{VP}}$. The net effect of these both parameters results in $\mathrm{Nu}_{\mathrm{CP}}<\mathrm{Nu}_{\mathrm{VP}}$, with the dominant effect of $\Delta \mathrm{T}$ rather than $\mathrm{k}$. It is observed that $\mathrm{Nu}$ values are predicted higher with VP as compared to CP by $13.55 \%$. Table 4 
shows that at $\mathrm{z} / \mathrm{D}=100$, the $\mathrm{Nu}$ is predicted higher for $\mathrm{VP}$ and $\mathrm{CP}$, as compared to conventional theoretical value of 4.36 .

Figure 8. Variation of Nusselt Number along the Flow with $u_{\text {in }}=3 \mathrm{~m} / \mathrm{s}, R=5 \times 10^{-5}$ $m$ and $q_{w}=100 \mathrm{~W} / \mathrm{cm}^{2}$ with $C P$, Properties $C_{p}(T), \rho(T), k(T)$ and $\mu(T)$ in Isolation and Combination $\left[C_{p}(T)+\rho(T)+k(T)+\mu(T)=V P\right]$

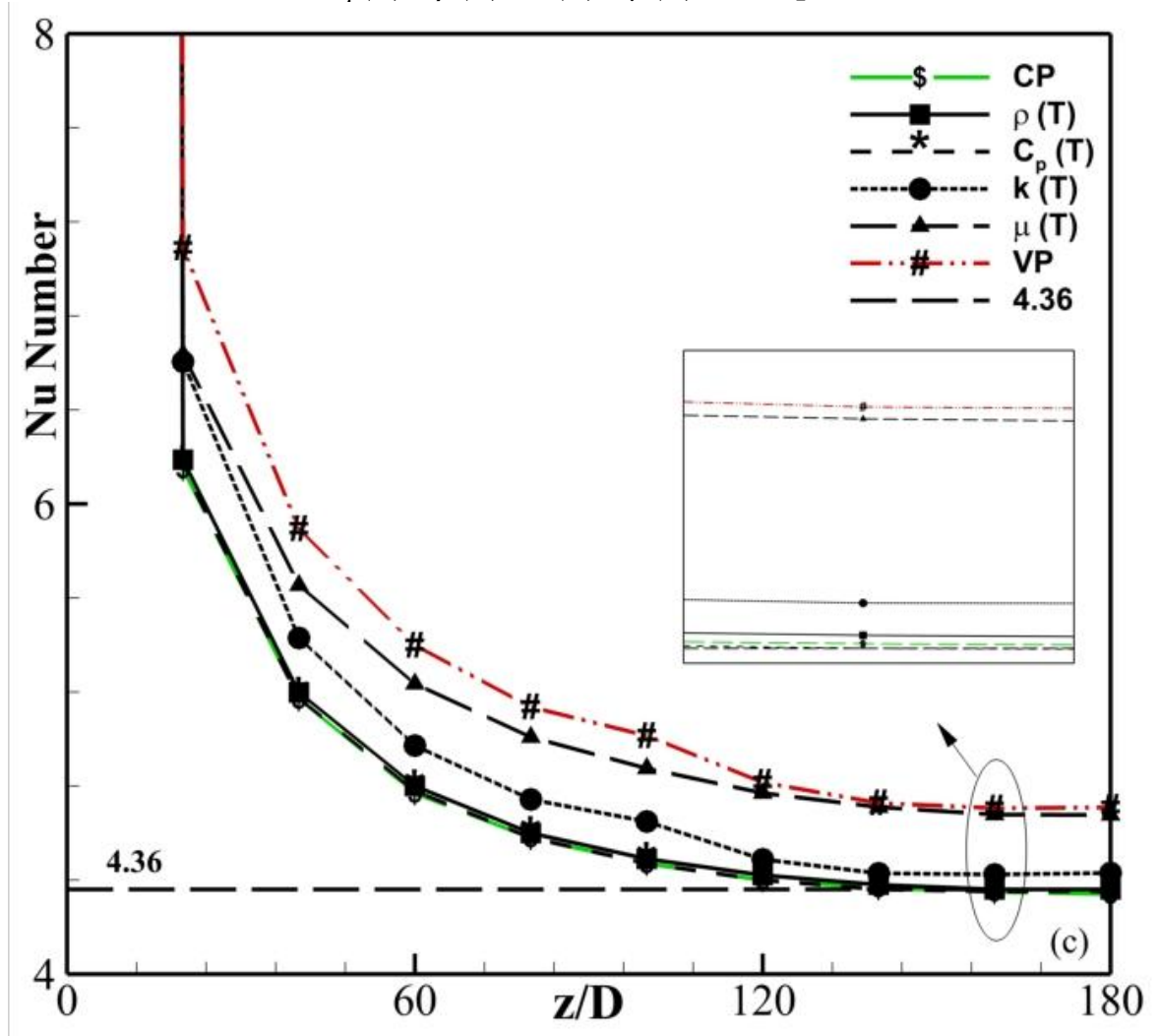

Table 4. Wall Temperature $T_{w}$, Mean Temperature $T_{m}$ and Nusselt Number Values at $z / D=180$ with Isolation Properties and their Combination (VP) compared to $C P$ with $u_{\text {in }}=3 \mathrm{~m} / \mathrm{s}, R=5 \times 10^{-5} \mathrm{~m}$ and $q_{w}=100 \mathrm{~W} / \mathrm{cm}^{2}$

\begin{tabular}{|l|c|c|c|}
\hline Property & $\mathrm{T}_{\mathrm{w}}$ & $\mathrm{T}_{\mathrm{m}}$ & Nu number \\
\hline $\mathrm{CP}$ & 369.01 & 331.15 & 4.34 \\
\hline$\rho(\mathrm{T})$ & 368.56 & 331.09 & 4.36 \\
\hline $\mathrm{C}_{\mathrm{p}}(\mathrm{T})$ & 368.45 & 331.08 & 4.35 \\
\hline $\mathrm{k}(\mathrm{T})$ & 366.14 & 331.17 & 4.42 \\
\hline$\mu(\mathrm{T})$ & 366.03 & 331.08 & 4.67 \\
\hline $\mathrm{VP}$ & 363.88 & 330.96 & 4.70 \\
\hline
\end{tabular}


Figure 9. Variation of (a) Skin Friction Coefficient $C_{f}(b)$ Darchy Friction Factor $f_{D}$ and (c) Normalized Pressure for Constant Properties (CP) and, Variable Properties $C_{p}(T), \rho(T), k(T)$ and $\mu(T)$ in Isolation, and in Combination $\left[C_{p}(T)+\rho(T)+k(T)+\mu(T)=V P\right]$
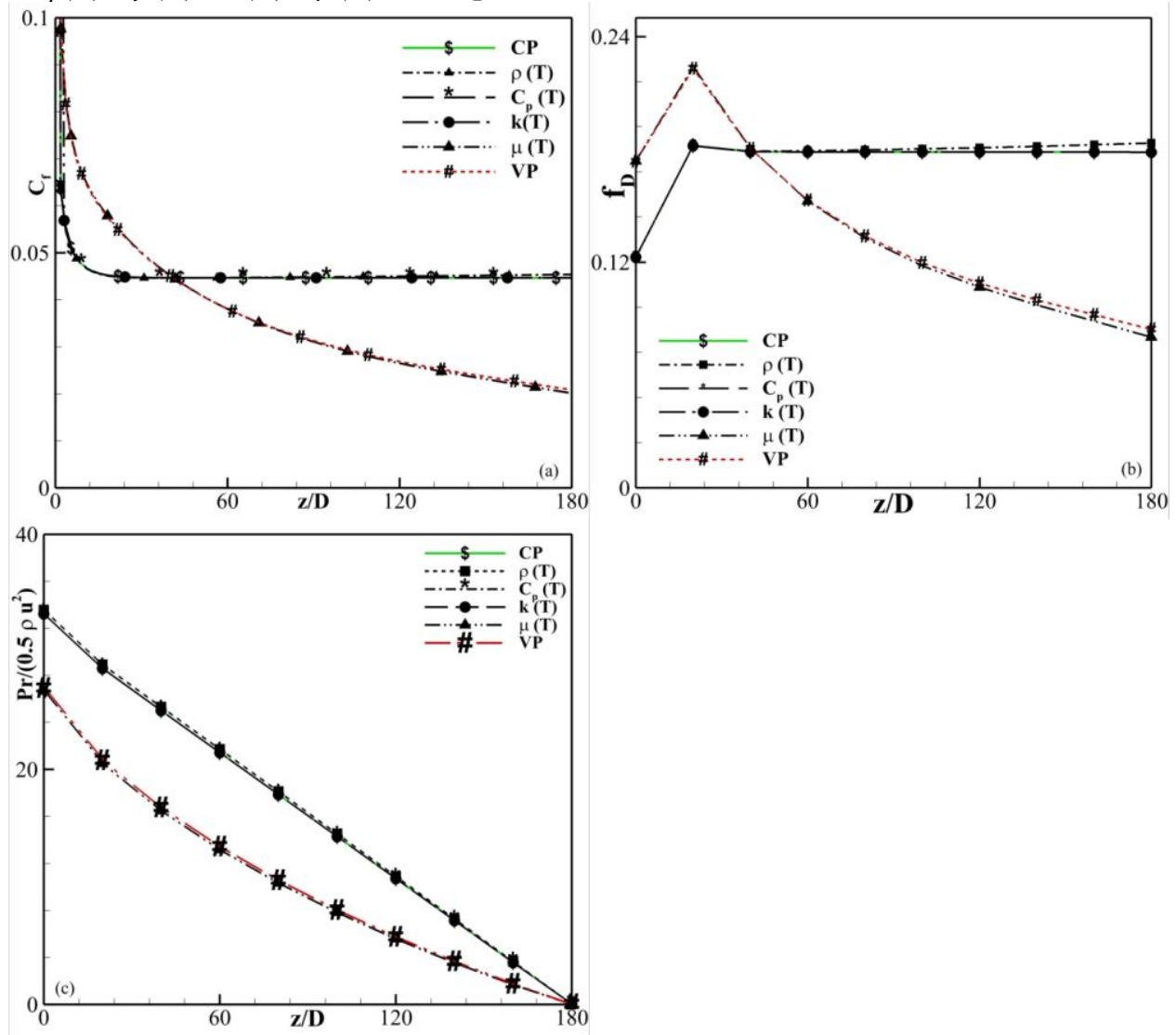

The $\mathrm{C}_{\mathrm{f}}$ in Figure $9 \mathrm{a}$ with $\mathrm{CP}$ decreases along the pipe to $\mathrm{z} / \mathrm{D}=24$ and remains constant downstream but $\mathrm{C}_{\mathrm{f}}$ with VP decreases to the end of the pipe and shows lower values at exit as compared to $\mathrm{CP}$. The Darchy friction factor in Figure $9 b$ increases upto $\mathrm{z} / \mathrm{D}=24$ for both $\mathrm{CP}$ and VP. Downstream of it remains constant for $\mathrm{CP}$ and decreases for VP. The pressure in Figure 9c shows linear drop with $\mathrm{CP}$ and non-linear drop with VP. The variation of $\mu(\mathrm{T})$ along the pipe changes in temperature hence changes the value of pressure with VP as compared to $\mathrm{CP}$. The other properties do not affect the pressure. The velocity profiles in Figure 4 shows that the velocity gradients are higher with $\mathrm{VP} z / \mathrm{D}=$ 50 as compared to $\mathrm{CP}$, therefore predicts higher values of $\mathrm{C}_{\mathrm{f}}$ as shown in Figure $9 \mathrm{a}$. Downstream of $\mathrm{z} / \mathrm{D}=50$, although the velocity gradients remain constant with $\mathrm{CP}$ and have lower values as compared to VP, the decrease in $\mu(T)$ with an increase in temperature along the pipe gives lower values of $C_{f}$ with VP as compared to CP as per Eq. 17. 


\section{Case 1: Variation of Radius}

Numerical simulations are performed with varying radii of $\mathrm{R}=5 \times 10^{-5} \mathrm{~m}$, $10 \times 10^{-5} \mathrm{~m}, 15 \times 10^{-5} \mathrm{~m}$ and $20 \times 10^{-5} \mathrm{~m}$ at a constant velocity and heat flux (see Table 1) In general, from Eqs 14 and 15, we infer that an increase in radius and decrease in $\Delta \mathrm{T}$ results in an increase in $\mathrm{Nu}$. Figure 10 shows that an increase in radii results in an increase of wall temperature $T_{w}$ and decrease of mean temperature $\mathrm{T}_{\mathrm{m}}$ for both CP and VP. This results in increase of $\Delta \mathrm{T}=\left(\mathrm{T}_{\mathrm{w}}-\mathrm{T}_{\mathrm{m}}\right)$ as shown in Figure 11, thereby reducing $\mathrm{Nu}$. But, the Figure 12 shows that $\mathrm{Nu}$ increases with increase in radii at CP and VP. This shows that increase in the dimension of pipe i.e. radius has influential effect as compared to $\Delta \mathrm{T}$ effect on $\mathrm{Nu}$. The difference in $\mathrm{Nu}$ between $\mathrm{CP}$ and VP increases with increase in radii. A difference of $14.50 \%, 17.33 \%$ and $19.20 \%$ is observed between $\mathrm{R}=5 \times 10^{-5}$ $\mathrm{m}, 1.5 \times 10^{-4} \mathrm{~m}$ and $2 \times 10^{-4} \mathrm{~m}$ respectively. Table 5 shows that $\mathrm{Nu}$ at $\mathrm{z} / \mathrm{L}=1$ has higher values for higher radii in developing flow regime. It is observed that $\mathrm{Nu}$ with $\mathrm{R}=5 \times 10^{-5} \mathrm{~m}$ is close to the conventional fully developed flow value of 4.36 for $\mathrm{CP}$ at exit and asymptotes to the correlation (Grigull and Tratz, 1965) at $\mathrm{z} / \mathrm{L}=0.5$, whereas for $\mathrm{VP}$ the $\mathrm{Nu}$ is higher at $\mathrm{Z} / \mathrm{L}=0.5$ and is still developing.

Figure 10. Variation of Wall Temperature $T_{w}$ and Mean Temperature $T_{m}$ compared for Constant Properties (CP) and Variable Properties (VP) along the Flow with Variable Radii at $u_{\text {in }}=3 \mathrm{~m} / \mathrm{s}$ and $q_{w}=100 \mathrm{~W} / \mathrm{cm}^{2}$

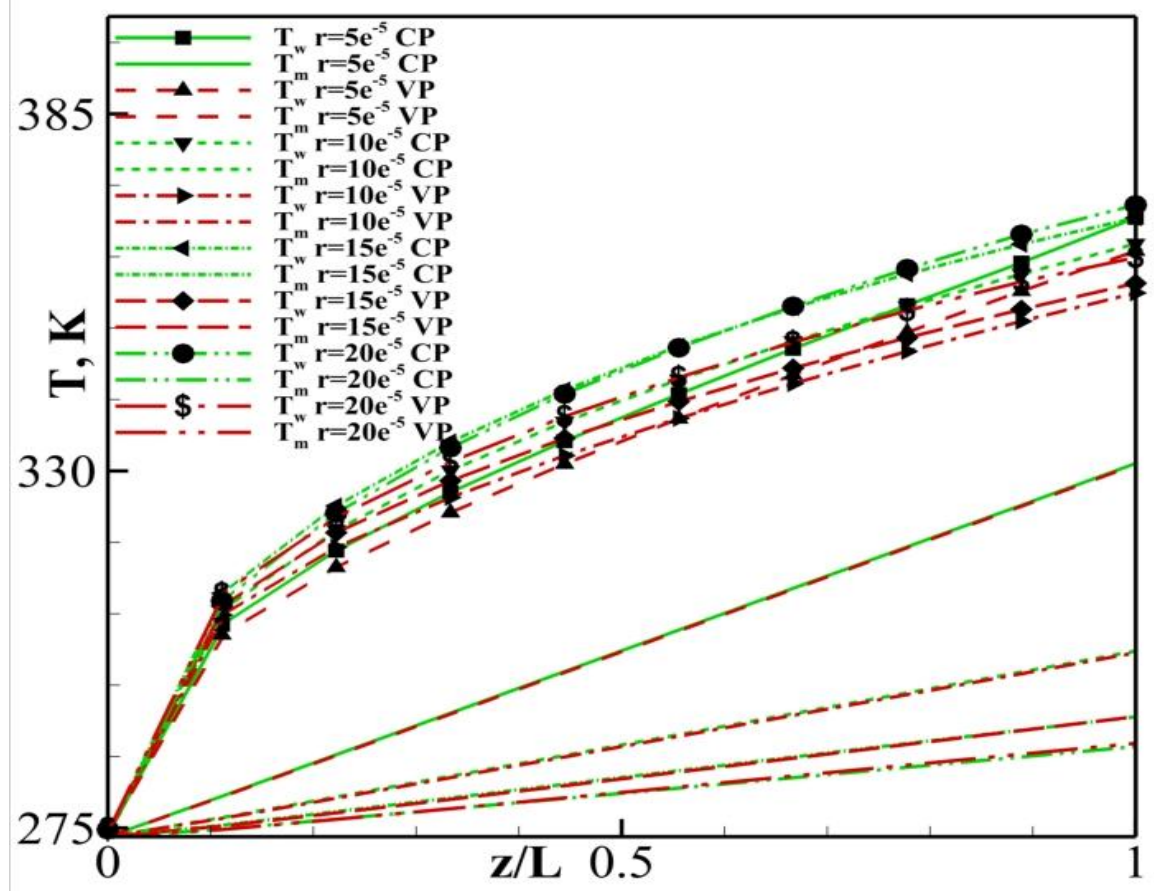


Figure 11. Variation of $\Delta T=\left(T_{w}-T_{m}\right)$ compared for Constant Properties $(C P)$ and Variable Properties (VP) along the Flow with Variable Radii at $u_{\text {in }}=3 \mathrm{~m} / \mathrm{s}$ and $q_{w}=100 \mathrm{~W} / \mathrm{cm}^{2}$

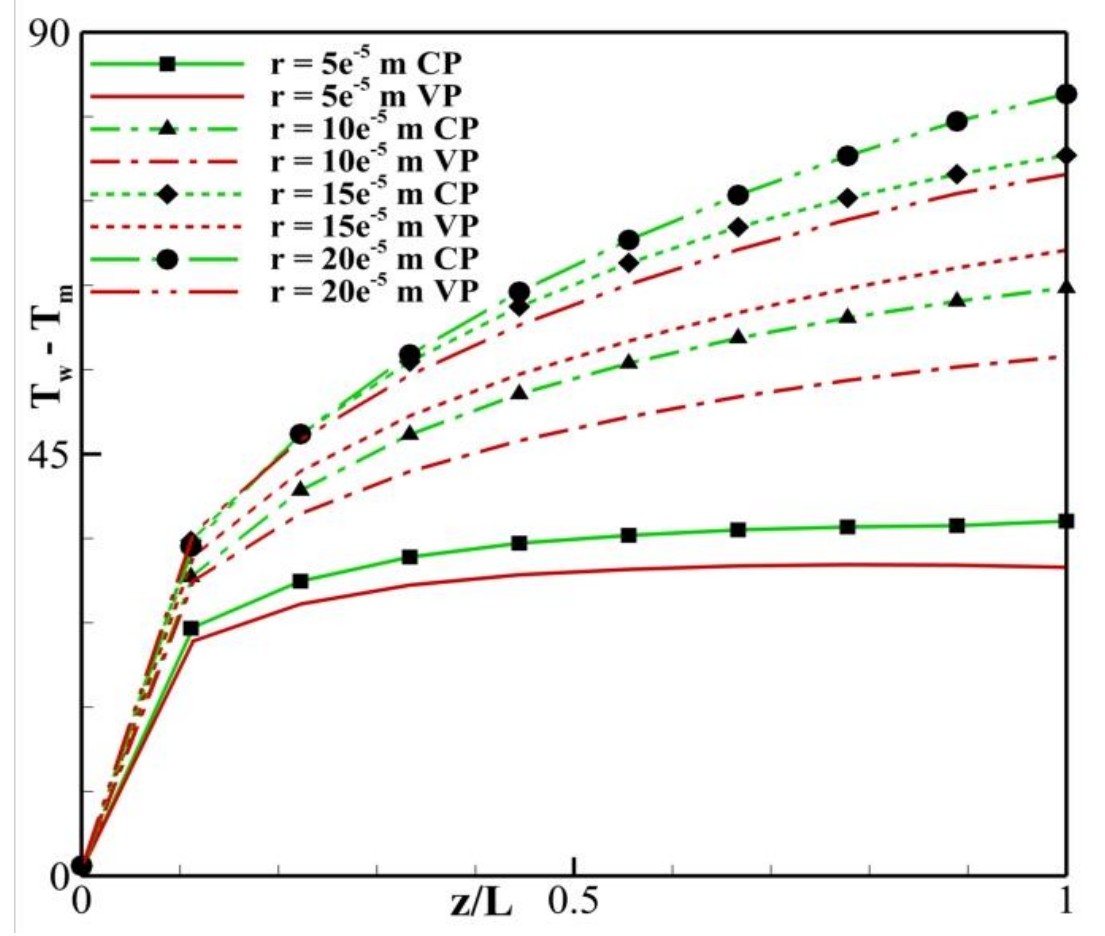

Figure 12. Comparison of Nusselt Number along the Flow with Variable Radii at $u_{\text {in }}=3 \mathrm{~m} / \mathrm{s}$, and $q_{w}=100 \mathrm{~W} / \mathrm{cm}^{2}$ with Constant Properties $(C P)$ and Variable Properties (VP)

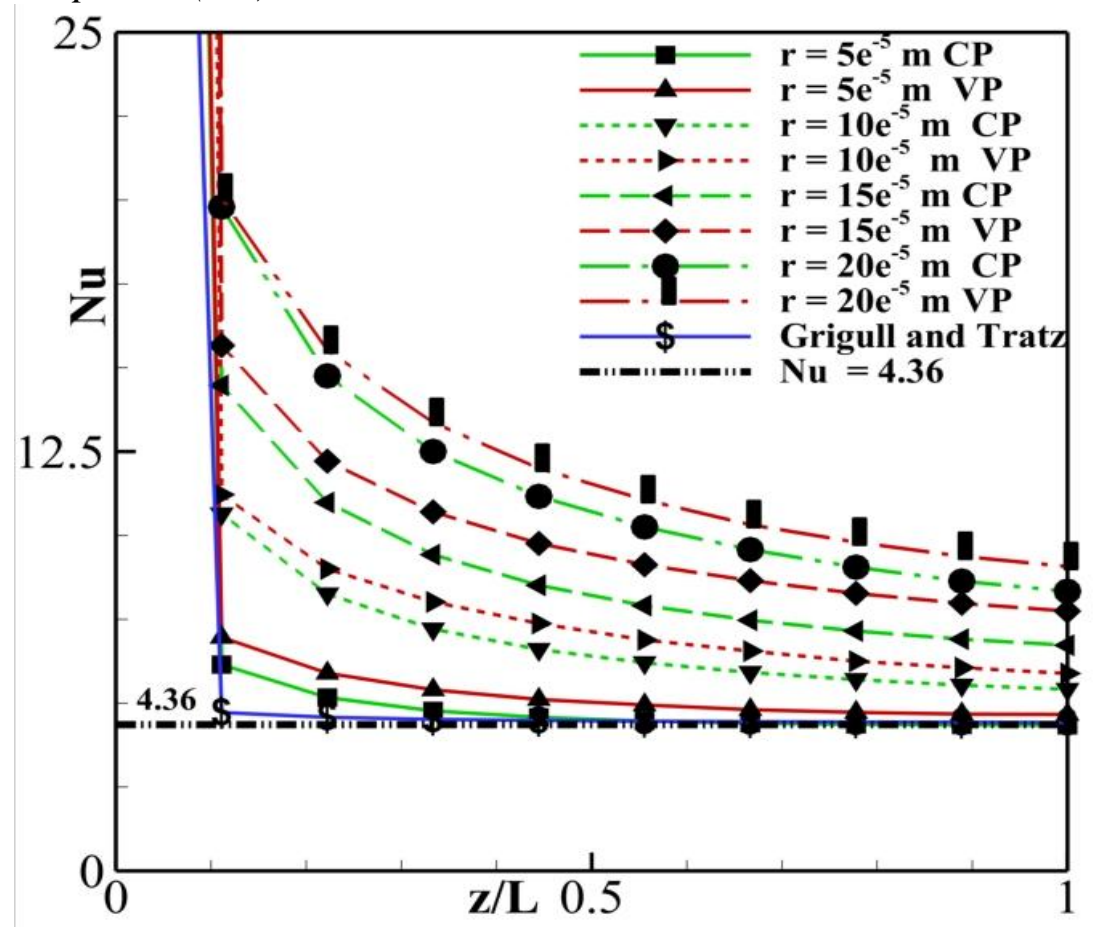


Table 5. Comparison of Wall Temperature $T_{w}$, Mean Temperature $T_{m}$ and Nusselt Number for $C P$ and VP at $z / L=1$ with Variable Radii at $u_{\text {in }}=3 \mathrm{~m} / \mathrm{s}$, and $q_{w}=$ $100 \mathrm{~W} / \mathrm{cm}^{2}$

\begin{tabular}{|c|c|c|c|}
\hline Radius (m) & $\mathrm{T}_{\mathrm{w}}$ & $T_{m}$ & Nu number \\
\hline CP $5 \times 10^{-5}$ & 342.74 & 305.55 & 4.54 \\
\hline VP $5 \times 10^{-5}$ & 337.94 & 305.58 & 5.25 \\
\hline $\mathrm{CP} 15 \times 10^{-5}$ & 351.61 & 283.63 & 7.48 \\
\hline VP $15 \times 10^{-5}$ & 340.47 & 283.63 & 8.90 \\
\hline $\mathrm{CP} 20 \times 10^{-5}$ & 355.19 & 281.62 & 9.13 \\
\hline VP $20 \times 10^{-5}$ & 342.65 & 281.66 & 11.07 \\
\hline
\end{tabular}

Figure 13. Variation of Computed (a) Friction Factor (b) Skin Friction (c) and Pressure Drop along the Pipe for Different Micro-pipe Radii compared with $C P$ and $V P$ at $u_{i n}=3 \mathrm{~m} / \mathrm{s}$ and $q_{w}=100 \mathrm{~W} / \mathrm{cm}^{2}$
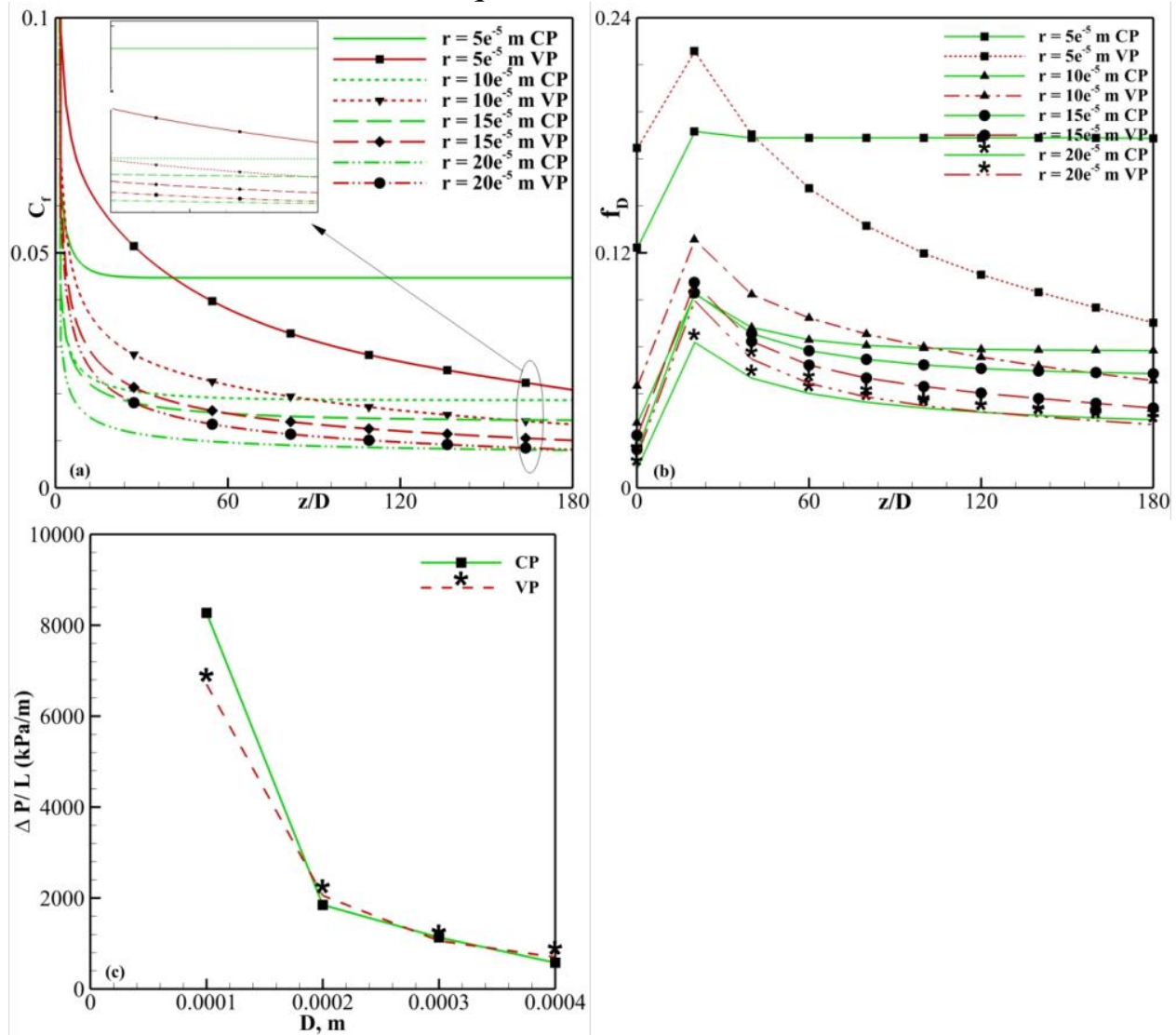

Figure 13 shows variation of skin friction $C_{f}$, friction factor $f_{D}$ and pressure drop $\Delta \mathrm{p}$ over pipe length $\mathrm{L}$ for $\mathrm{CP}$ and $\mathrm{VP}$ at inlet velocity of $\mathrm{u}_{\mathrm{in}}=3 \mathrm{~m} / \mathrm{s}$ and $\mathrm{q}_{\mathrm{w}}=100 \mathrm{~W} / \mathrm{cm}^{2}$. The $\mathrm{z}$-axis is non-dimensioned with $\mathrm{D}=10^{-4} \mathrm{~m}$. Figure $13 \mathrm{a}$ shows that as the diameter of pipe is increased the $\mathrm{C}_{\mathrm{f}}$ decreases with VP and shows lower values. The flow exhibits lower velocity gradients for higher diameters, therefore results in lower values of $\mathrm{C}_{\mathrm{f}}$. Figure $13 \mathrm{~b}$ and $13 \mathrm{c}$ shows a decrease in $\Delta \mathrm{p}$ and a decrease in $f_{D}$. This decrease is due to the fact that the contact surface area reduces for the same inlet velocity and mass flow rate. 
Moreover for smaller radii, pressure drop and friction factor being more and this reduces with increasing radii. The friction factor shows a constant trend for all the radii but for VP it reduces continuously.

\section{Case 2: Variation of Inlet Velocities}

In this section we study the effect of different inlet velocities with $u_{i n}=3 \mathrm{~m} / \mathrm{s}$, $7.5 \mathrm{~m} / \mathrm{s}$ and $15 \mathrm{~m} / \mathrm{s}$ as shown in Table 1 . This corresponds to different Reynolds number flows of 276, 690, 1383. Figure 14 shows that with increase in inlet velocities, $\mathrm{T}_{\mathrm{w}}$ and $\mathrm{T}_{\mathrm{m}}$ for both $\mathrm{VP}$ and $\mathrm{CP}$ decrease, resulting in decrease in $\Delta \mathrm{T}$ as shown in Figure 15. This results in higher values of $\mathrm{Nu}$ for higher inlet velocities for both CP and VP and is shown in Figure 16. It is to be noted that $\mathrm{Nu}$ with $3 \mathrm{~m} / \mathrm{s}$ inlet velocity is almost close to the conventional fully developed flow value of 4.36 for $\mathrm{CP}$ at exit and asymptotes to the correlation (Grigull and Tratz, 1965) for developing flow at $\mathrm{Z} / \mathrm{D}=100$. The differences between $\mathrm{Nu}$ for CP and VP are $13.93 \%, 11.11 \%$ and $8.82 \%$ for $\mathrm{u}_{\text {in }}=3 \mathrm{~m} / \mathrm{s}, 7.5 \mathrm{~m} / \mathrm{s}$ and $15 \mathrm{~m} / \mathrm{s}$ respectively. Table 6 shows that higher inlet velocities lead to delay in fully thermally developed flow.

Figure 14. Variation of Wall Temperature $T_{w}$ and Mean Temperature $T_{m}$ compared for Constant Properties (CP) and Variable Properties (VP) along the Flow with Variable Inlet Velocities at $R=5 \times 10^{-5} \mathrm{~m}_{\text {and }} q_{w}=100 \mathrm{~W} / \mathrm{cm}^{2}$

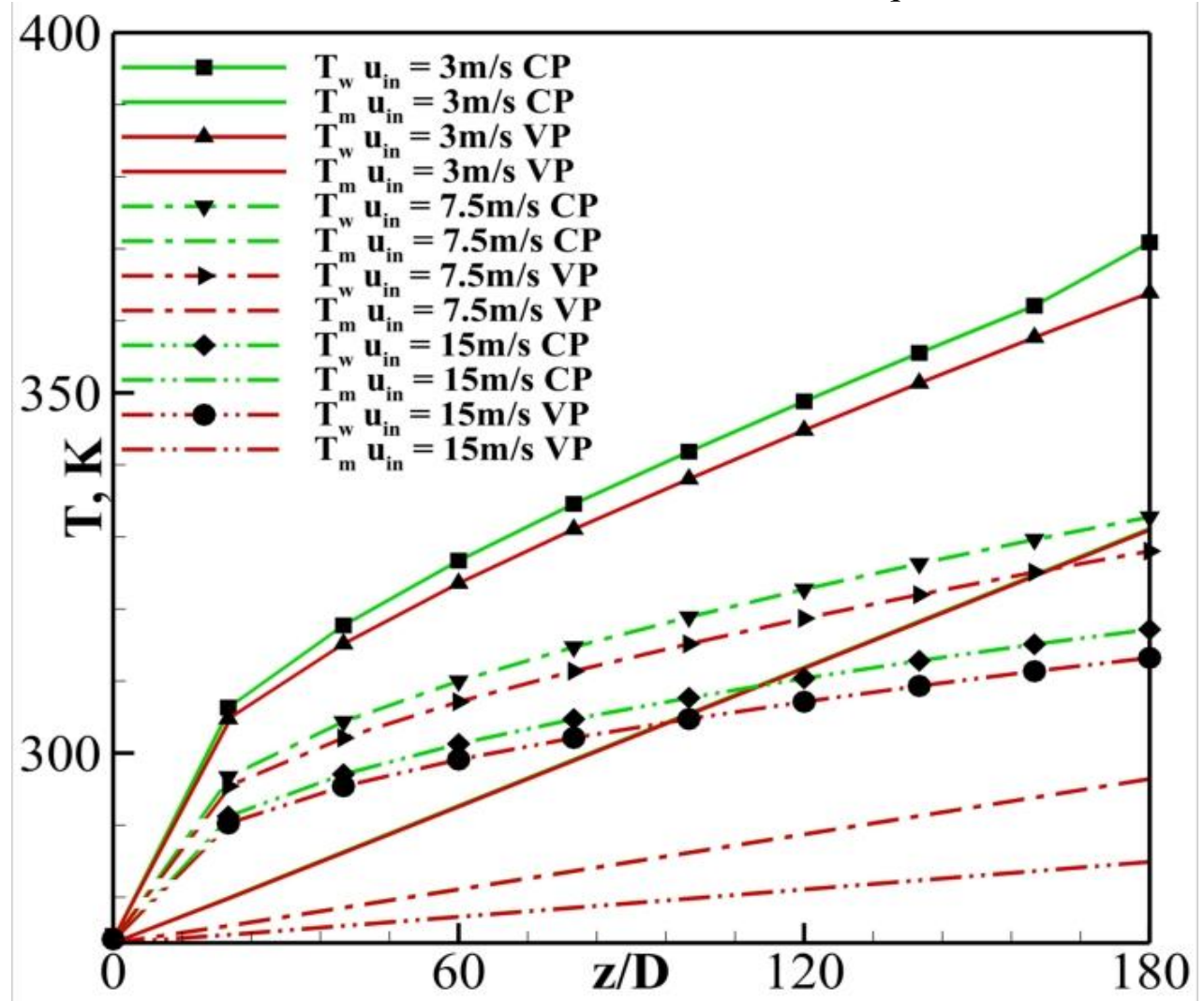


Figure 15. Variation of $\Delta T=\left(T_{w}-T_{m}\right)$ compared for Constant Properties $(C P)$ and Variable Properties (VP) along the Flow with Variable Inlet Velocities at $R=5 \times 10^{-5} \mathrm{~m}$ and $q_{w}=100 \mathrm{~W} / \mathrm{cm}^{2}$

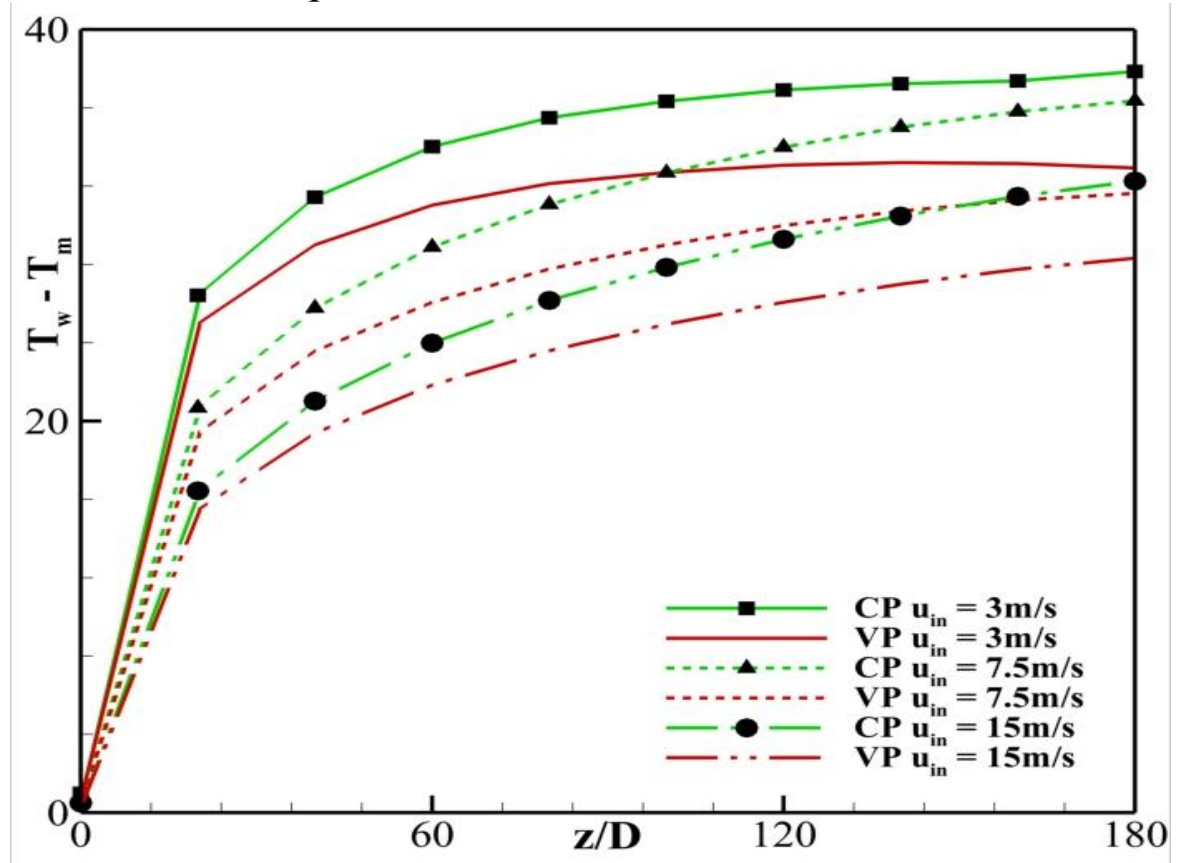

Figure 16. Variation of Nusselt Number along the Flow with Variable Inlet Velocities at $R=5 \times 10^{-5} \mathrm{~m}$ and $q_{w}=100 \mathrm{~W} / \mathrm{cm}^{2}$ compared with Constant Properties $(C P)$ and Variable Properties (VP)

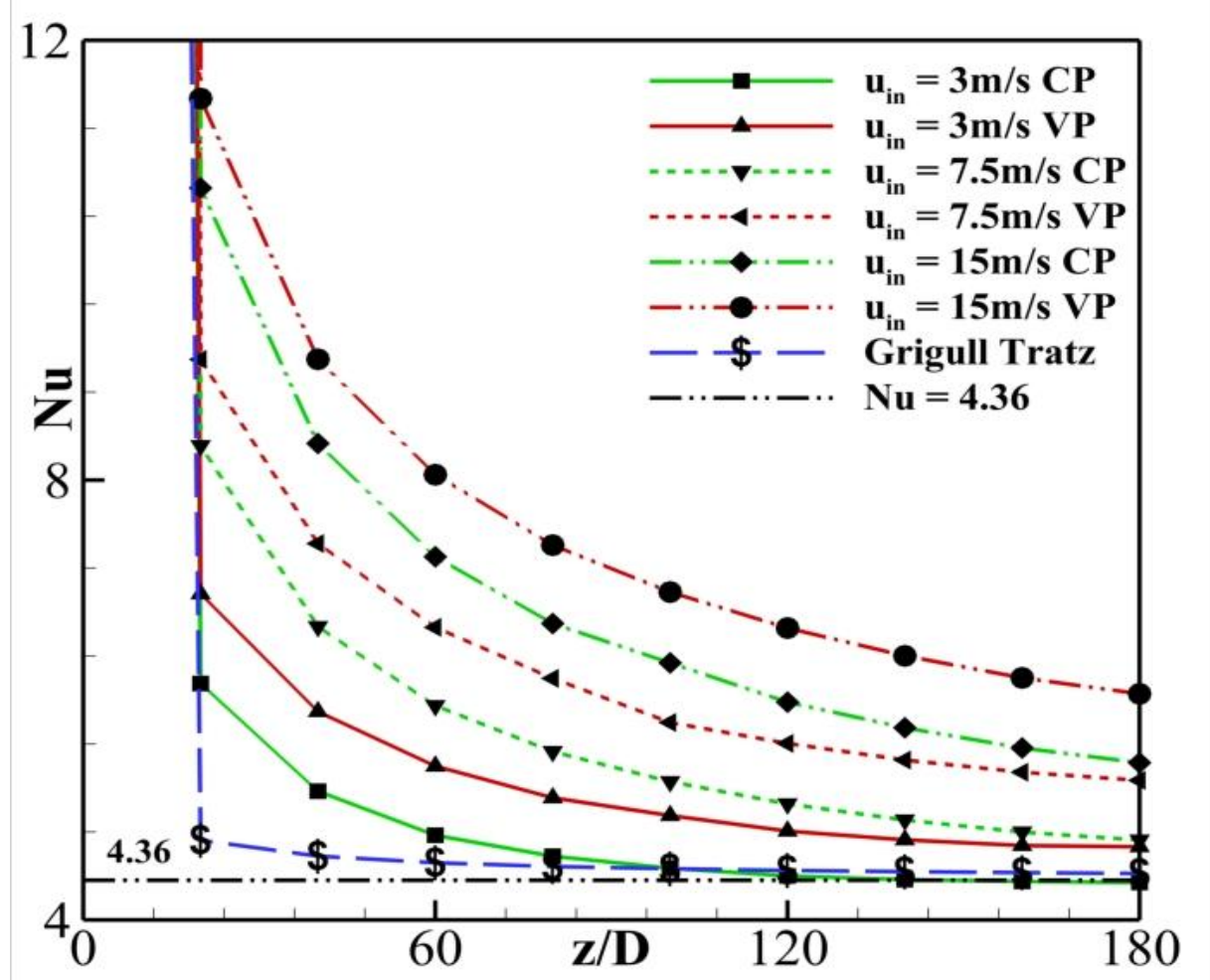


Figure 17. Comparison of Computed (a) Friction Factor (b) Skin Friction (c) Pressure Drop for Different Inlet Velocities with $C P$ and VP for $R=5 \times 10^{-5}$ and $q_{w}=100 \mathrm{~W} / \mathrm{cm}^{2}$
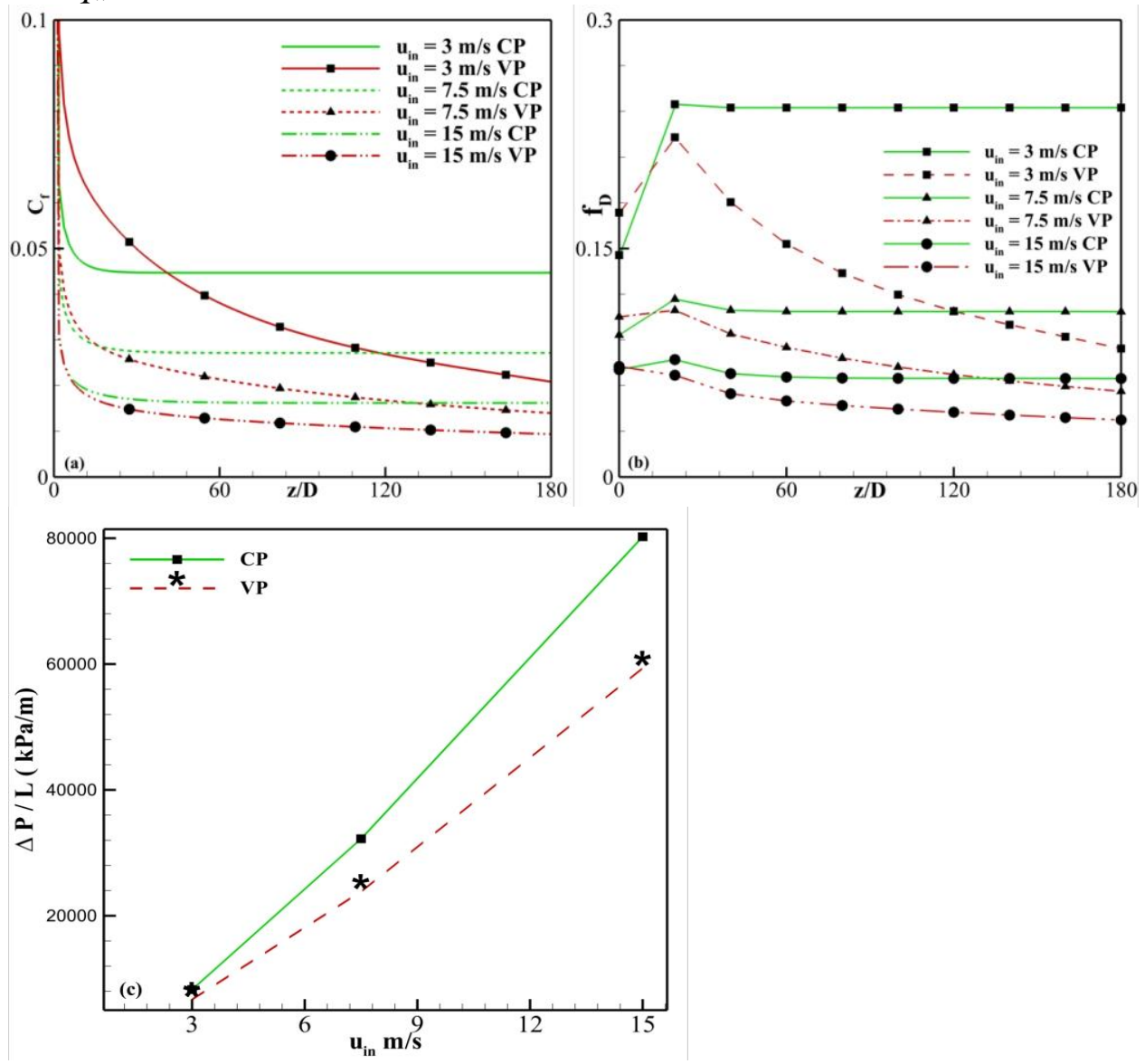

Table 6. Wall Temperature $T_{w}$, Mean Temperature $T_{m}$ and Nusselt Number Values at $z / D=100$ compared to $C P$ and $V P$, with Variable Inlet Velocities at $R=$ $5 \times 10^{-5} \mathrm{~m}$, and $q_{w}=100 \mathrm{~W} / \mathrm{cm}^{2}$

\begin{tabular}{|l|c|c|c|}
\hline Velocity $\mathrm{m} / \mathrm{s}$ & $\mathrm{T}_{\mathrm{w}}$ & $\mathrm{T}_{\mathrm{m}}$ & Nu number \\
\hline CP 3 & 342.73 & 305.55 & 4.54 \\
\hline VP 3 & 337.93 & 305.56 & 5.22 \\
\hline CP 7.5 & 318.45 & 286.42 & 5.27 \\
\hline VP 7.5 & 315.08 & 286.42 & 5.89 \\
\hline CP 15 & 306.95 & 280.04 & 6.28 \\
\hline VP 15 & 304.66 & 280.04 & 6.86 \\
\hline
\end{tabular}

Figure 17a shows that as the inlet velocity is increased the $\mathrm{C}_{\mathrm{f}}$ decreases for $\mathrm{VP}$ for $\mathrm{R}=5 \times 10^{-5} \mathrm{~m}$ and $\mathrm{q}_{\mathrm{w}}=100 \mathrm{~W} / \mathrm{cm}^{2}$. Figure $17 \mathrm{~b}$ shows a friction factor $f_{D}$ plot with different inlet velocities. With smaller velocities i.e. $3 \mathrm{~m} / \mathrm{s}$ the friction factor is very high and there is a huge deviation between CP and VP compared to other velocities. As the velocities are increasing the friction decreases and becomes constant for CP while for VP it drops continuously. Figure $17 \mathrm{c}$ 
shows that pressure drop increases drastically with an increase in inlet velocity and the deviation of pressure drop from $\mathrm{CP}$ to $\mathrm{VP}$ increases as the inlet velocity increases. The values of pressure drop are lower for VP as compared to CP.

Case 3: Variation of Wall Heat Flux

Figure 18. Variation of Wall Temperature $T_{w}$ and Mean Temperature $T_{m}$ compared for Constant Properties (CP) and Variable (VP) along the Flow with Variable Wall Heat Flux at $u_{\text {in }}=3 \mathrm{~m} / \mathrm{s}$, and $R=5 \times 10^{-5} \mathrm{~m}$

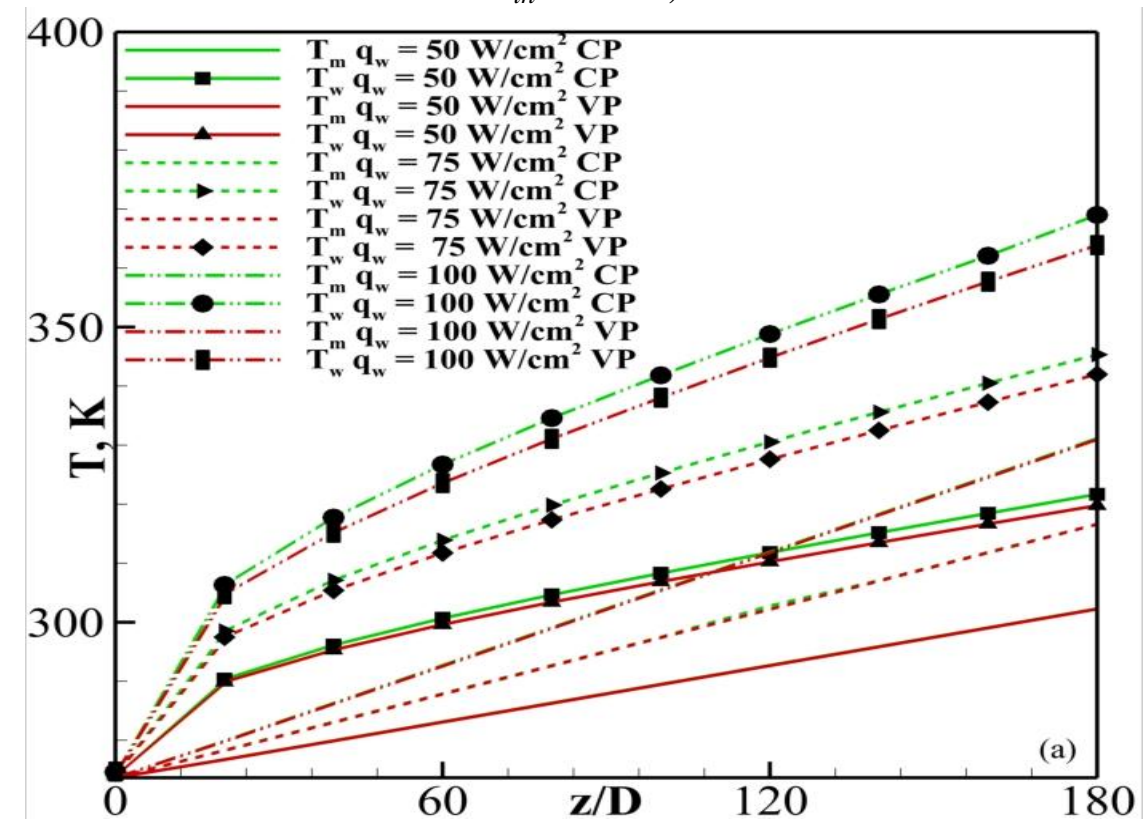

Figure 19. Variation of $\Delta T=\left(T_{w}-T_{m}\right)$ compared for Constant Properties $(C P)$ and Variable Properties (VP) along the Flow with Variable Wall Heat Flux at $u_{\text {in }}=3 \mathrm{~m} / \mathrm{s}$, and $R=5 \times 10^{-5} \mathrm{~m}$

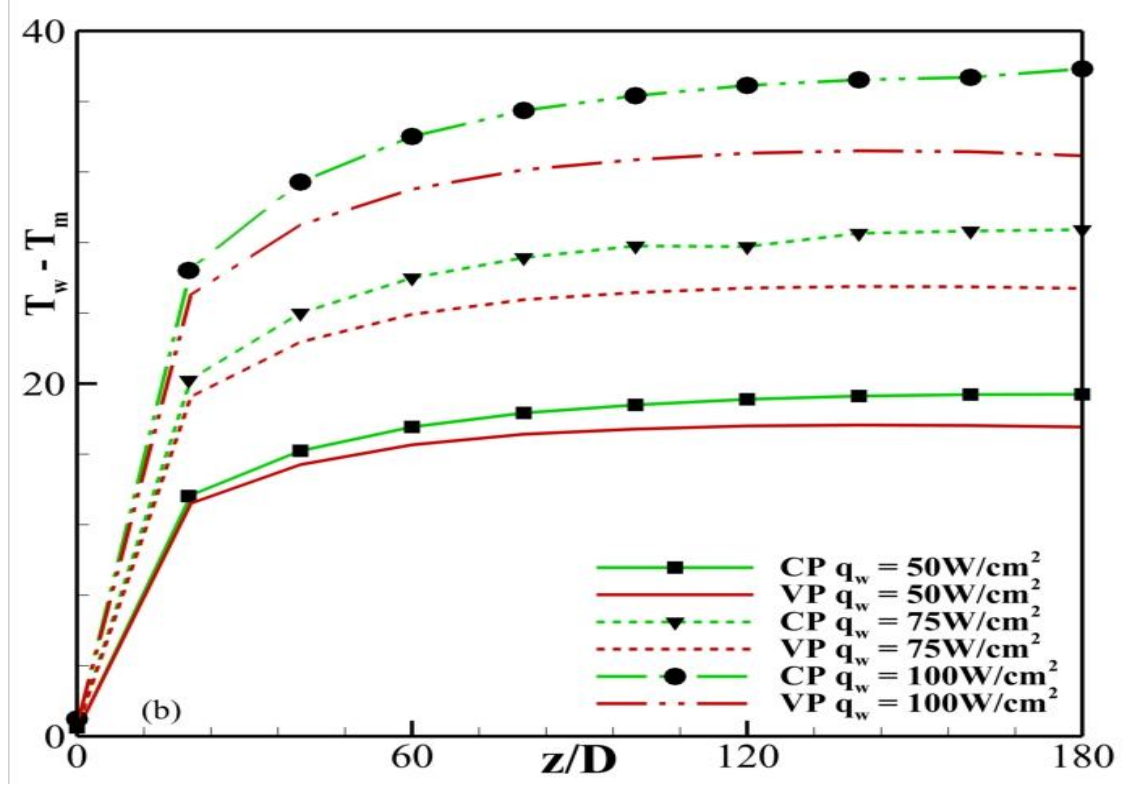


Figure 20. Variation of Nusselt Number along the Flow with Variable Wall Heat Flux at $u_{\text {in }}=3 \mathrm{~m} / \mathrm{s}$, and $R=5 \times 10^{-5}$ m compared with Constant Properties $(C P)$ and Variable Properties (VP)

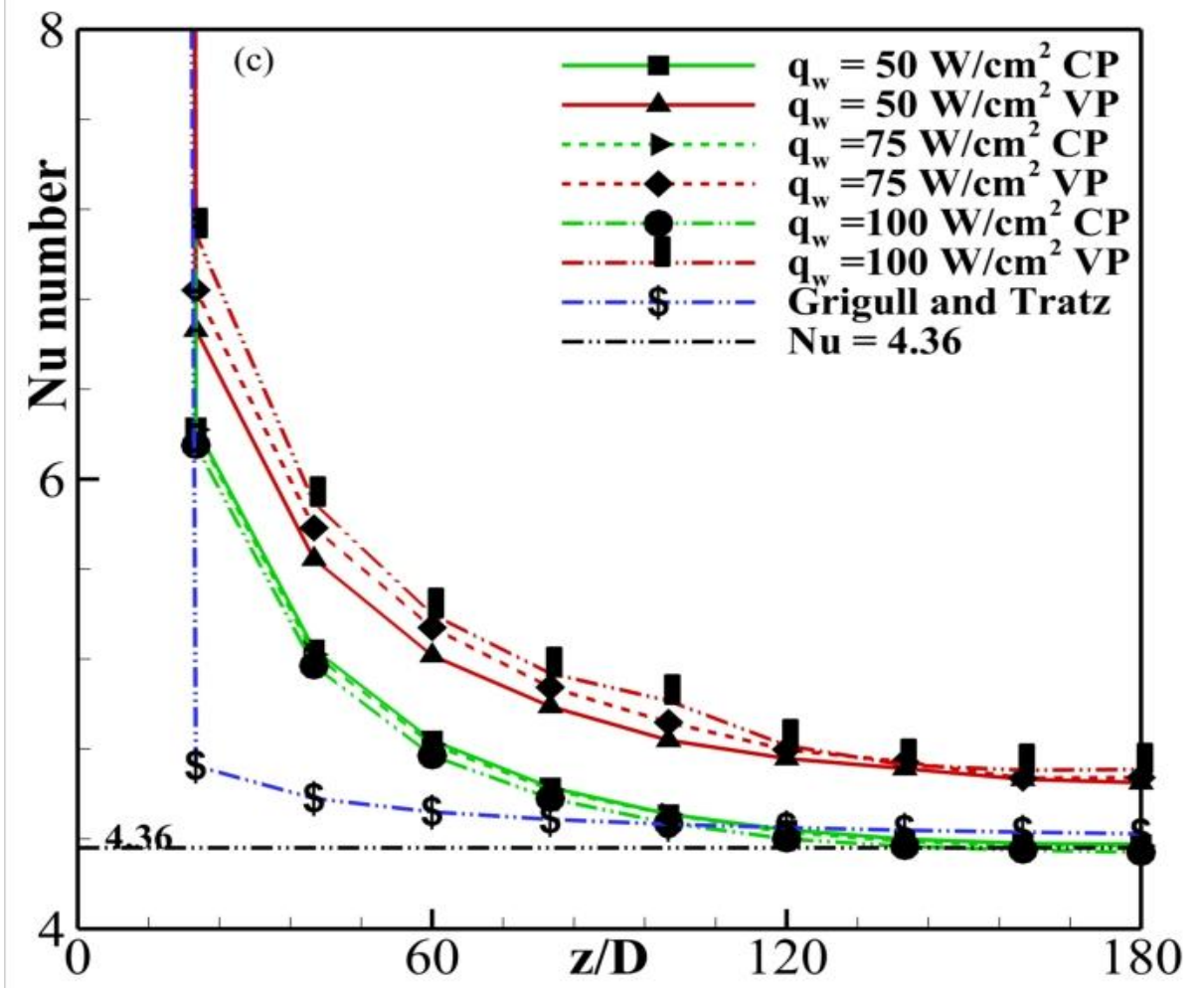

Table 7. Wall Temperature $T_{w}$, Mean Temperature $T_{m}$ and Nusselt Number Values at $z / D=100$ compared to $C P$ and VP, with Variable Wall Heat Fluxes, at $u_{\text {in }}=$ $3 \mathrm{~m} / \mathrm{s}$, and $R=5 \times 10^{-5} \mathrm{~m}$

\begin{tabular}{|l|c|c|c|}
\hline Heat flux $\mathrm{q}_{\mathrm{w}}\left(\mathrm{W} / \mathrm{cm}^{2}\right)$ & $\mathrm{T}_{\mathrm{w}}$ & $\mathrm{T}_{\mathrm{m}}$ & $\mathrm{Nu}$ \\
\hline CP 50 & 308.19 & 289.56 & 4.53 \\
\hline VP 50 & 306.89 & 289.60 & 4.87 \\
\hline CP 100 & 342.73 & 305.55 & 4.55 \\
\hline VP 100 & 337.93 & 305.51 & 5.23 \\
\hline CP 140 & 370.25 & 318.32 & 4.88 \\
\hline VP 140 & 362.36 & 318.19 & 5.76 \\
\hline
\end{tabular}

In this case study (see Table 1) different wall heat flux values $\mathrm{q}_{\mathrm{w}}$ of 50 $\mathrm{W} / \mathrm{cm}^{2}, 100 \mathrm{~W} / \mathrm{cm}^{2}$ and $140 \mathrm{~W} / \mathrm{cm}^{2}$ are assumed. In this case, the Nu majorly depends on two parameters; $\mathrm{q}_{\mathrm{w}}$ and temperature difference, $\Delta \mathrm{T}=\left(\mathrm{T}_{\mathrm{w}}-\mathrm{T}_{\mathrm{m}}\right)$ as given by Eqs 14 and 15. Figure 18 shows that as $\mathrm{q}_{\mathrm{w}}$ is increased, both $\mathrm{T}_{\mathrm{w}}$ and $\mathrm{T}_{\mathrm{m}}$ increases for CP and VP. This results in increase of $\Delta \mathrm{T}$ as shown in Figure 19 and causes decrease in values of $\mathrm{Nu}$. But the amount of increase in $\mathrm{q}_{\mathrm{w}}$ dominates and causes an increase in $\mathrm{Nu}$ as shown in Figure 20. A difference of $7.23 \%, 13.98 \%, 16.54 \%$ in $\mathrm{Nu}$ is observed at $\mathrm{q}_{\mathrm{w}}=50 \mathrm{~W} / \mathrm{cm}^{2}, 100 \mathrm{~W} / \mathrm{cm}^{2}$ and $140 \mathrm{~W} / \mathrm{cm}^{2}$ for CP and VP respectively. Table 7 shows that higher values of $\mathrm{q}_{\mathrm{w}}$ 
results in higher lengths of thermally developed flow based on Nusselt number values.

Figure 21. Variation of (a) Skin Friction Coefficient (b) Darchy Friction Factor and (c) Pressure Drop for Different Heat Fluxes compared with CP and VP with Variable Wall Heat Fluxes, at $u_{\text {in }}=3 \mathrm{~m} / \mathrm{s}$, and $R=5 \times 10^{-5} \mathrm{~m}$
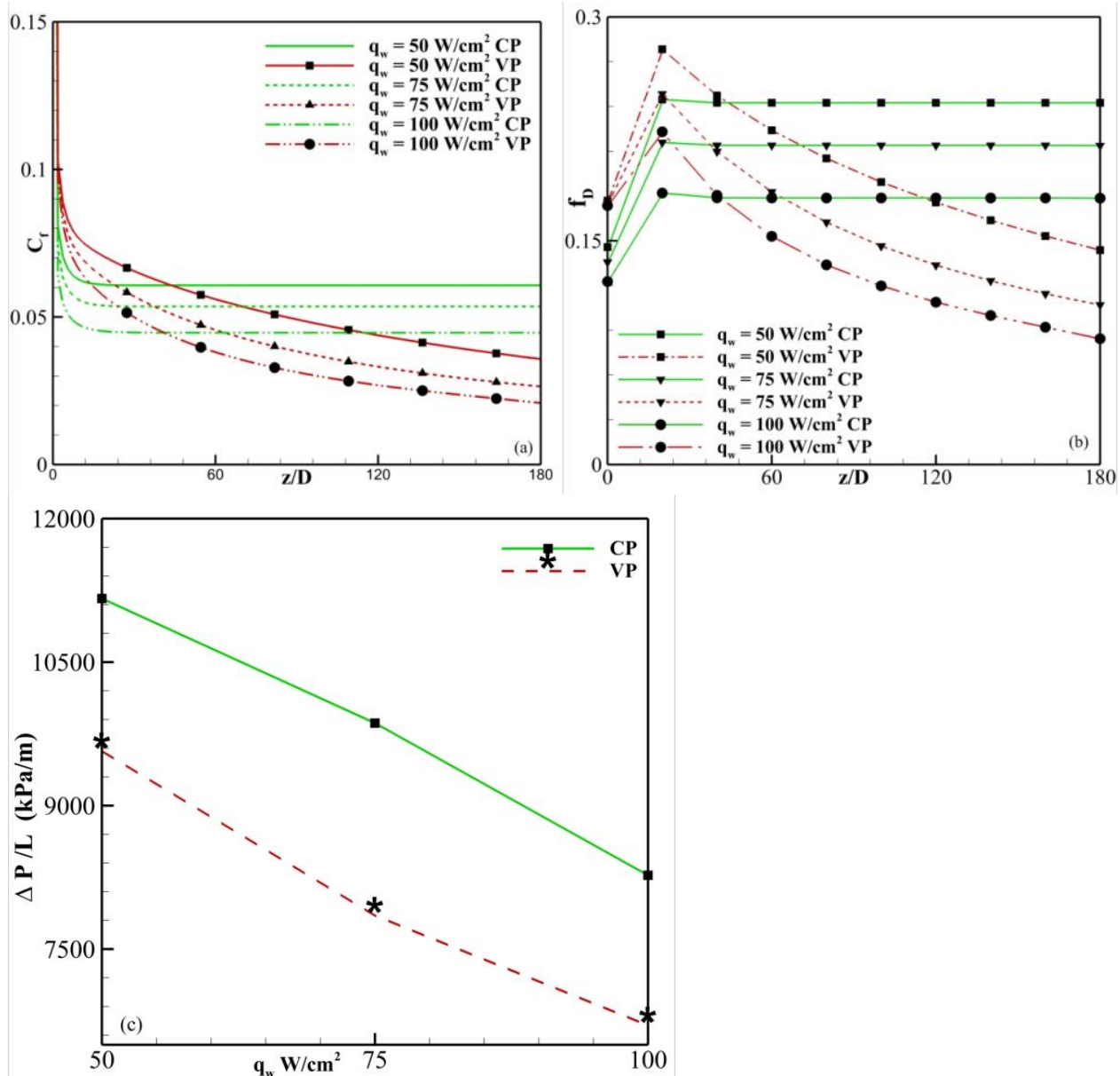

Figure 21 a shows that for a $5 \times 10^{-5} \mathrm{~m}$ pipe radius and inlet velocity of $\mathrm{u}_{\mathrm{in}}=3$ $\mathrm{m} / \mathrm{s}$, increasing the heat flux, decreases the skin friction $\mathrm{C}_{\mathrm{f}}$. The higher values of heat flux results in higher wall temperature thereby reduce the values of $\mu(T)$, hence the $C_{f}$. In Figure $21 \mathrm{~b}$, the friction factor decreases with increasing heat fluxes but shows a constant trend for all the given heat fluxes for CP. But for VP it drops continuously below the CP values. Figure 21c shows that for a $5 \times 10^{-5} \mathrm{~m}$ pipe radius and inlet velocity of $u_{i n}=3 \mathrm{~m} / \mathrm{s}$ increasing heat flux, pressure drop continuously decreases. It is seen that pressure drop for both the $\mathrm{CP}$ and VP is almost linearly reducing, but with a huge difference between them. This is because of large temperature gradient $\mathrm{q}_{\mathrm{w}}$ at the wall, which reduces the viscosity, reducing the frictional pressure drop. 


\section{Correlation of Nusselt Number with Reynolds Numbers and Heat Flux}

Figure 22 shows inlet Reynolds number, $\operatorname{Re}_{\infty}$ variation with the Nusselt number, $\mathrm{Nu}$. The $\mathrm{Re}_{\infty}$ is calculated for different velocities in case-1, and at different diameters for Case 2. It is observed that as the velocity increases, the $\mathrm{Nu}$ increases. Moreover, $\mathrm{Nu}$ being greater for VP than $\mathrm{CP}$. But as the radius increases, there is a huge increase in $\mathrm{Nu}$ number compared to an increase in velocities. In Figure 23 the $\mathrm{Nu}$ is compared with increasing heat flux values. It is observed that $\mathrm{Nu}$ is greater for $\mathrm{VP}$ as compared to $\mathrm{CP}$ and both deviate with an increase in heat flux values.

Figure 22. Correlation of Nusselt Number at Pipe Exit with Variation of Radius and Inlet Velocities for Cases 1 and 2

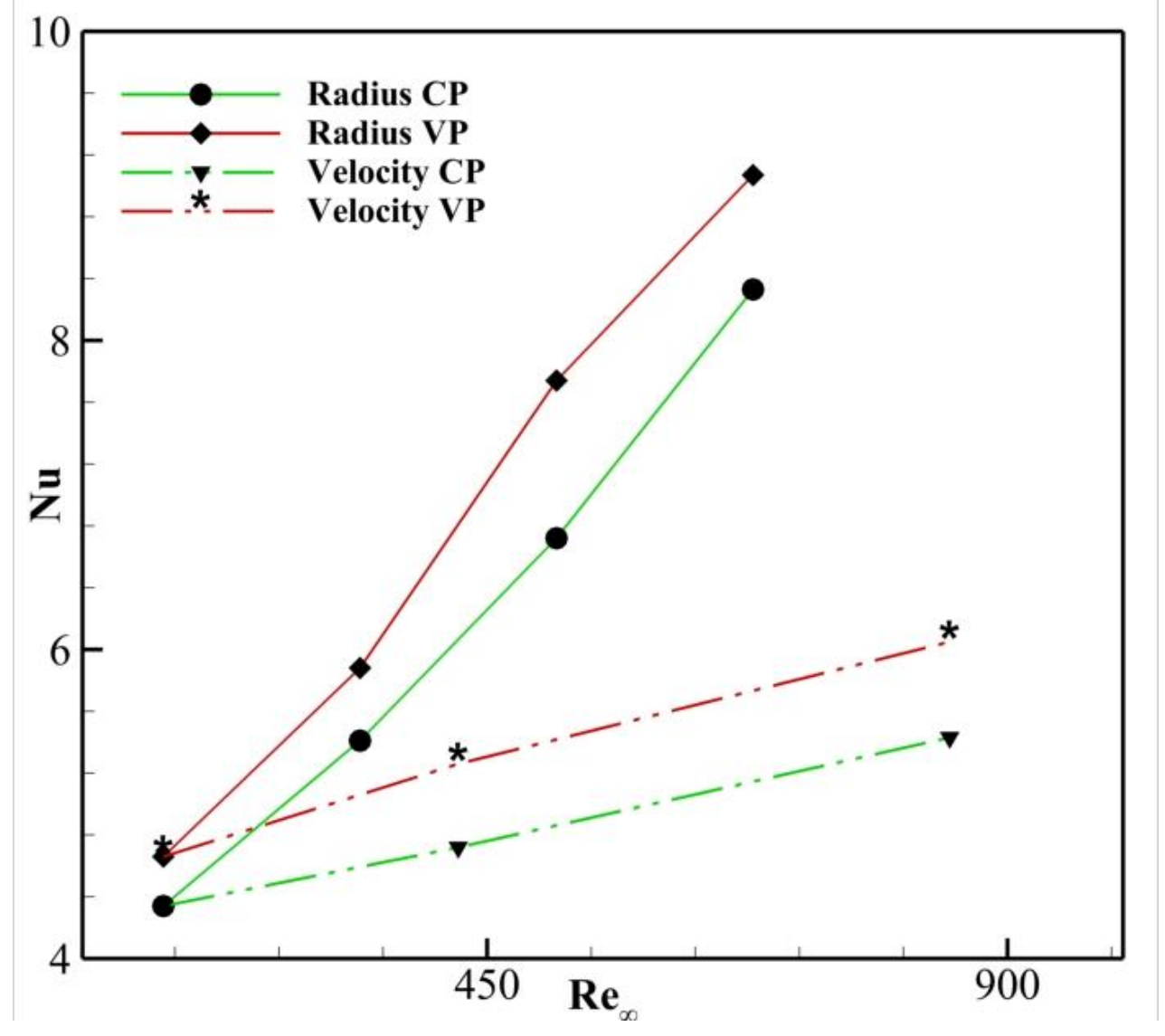


Figure 23. Correlation of Nusselt Number at Pipe Exit with Variation of Heat Flux Rates for Case 3

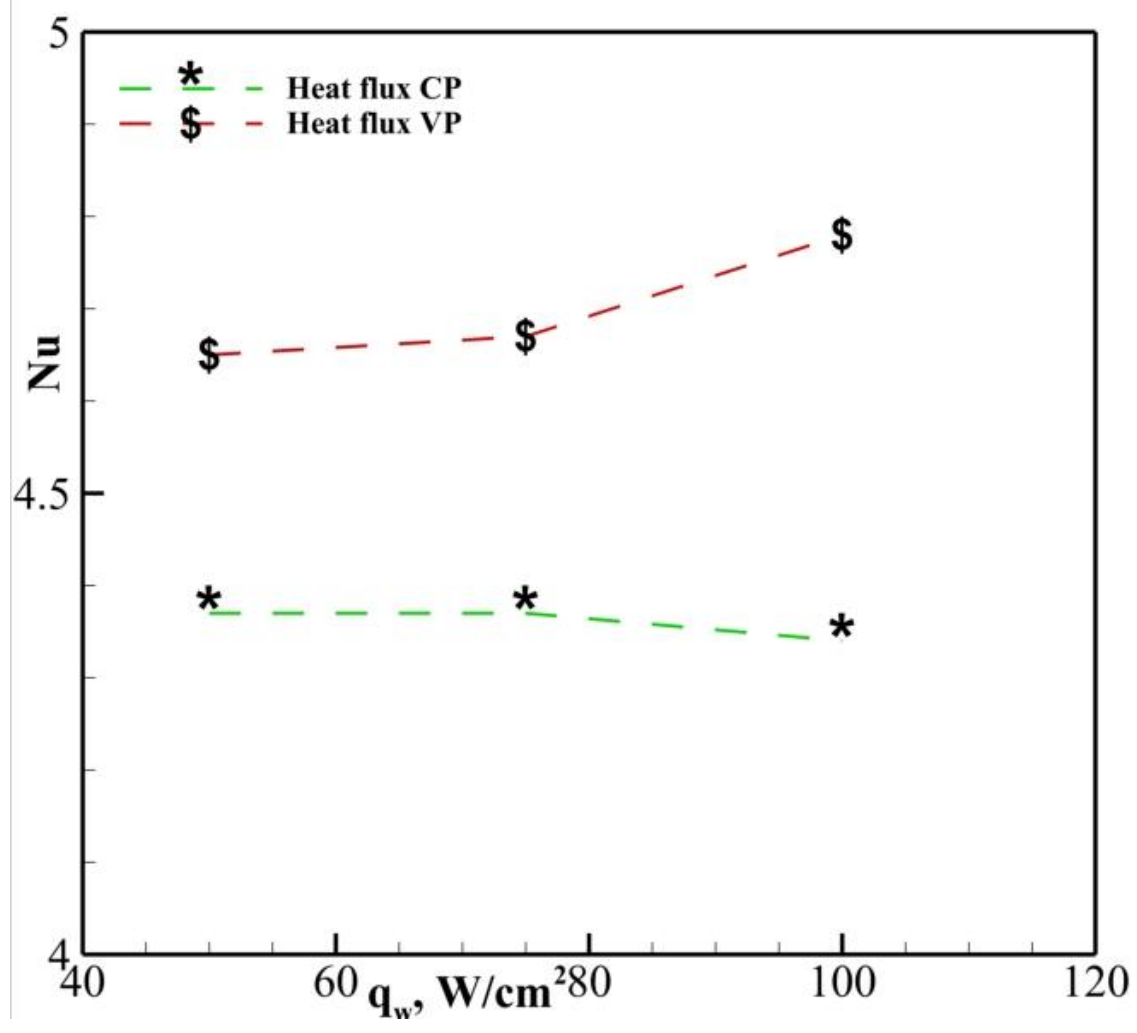

\section{Conclusions}

Numerical simulations are performed for two-dimensional axisymmetric micro pipe with entrance effects, for steady, laminar, incompressible and single phase liquid water with constant properties $\mathrm{CP}$ and variable properties VP flows.

First, the isolation effect of $C_{p}(T), \rho(T), k(T)$ and $\mu(T)$ and their combined effect on mean $T_{m}$ and wall temperature $T_{w}$ is studied. It is observed that the wall temperature obtained with $\mathrm{k}(\mathrm{T})$ and $\mu(\mathrm{T})$ variations shows lower values as compared to $\mathrm{CP}$ flows and the negligible effect is observed with variation of $C_{p}(T)$ and $\rho(T)$. Therefore the combined effect of variations in properties $C_{p}(T)$, $\rho(T), k(T)$ and $\mu(T)$ give lower values of $T_{w}$ as compared to $C P$ flows. The variation of $T_{m}$ is not affected and is same for both $C P$ and VP. Therefore, the Nusselt number at variable property flows $\mathrm{Nu}_{\mathrm{VP}}$ is predicted higher as compared to Nusselt number at constant property $\mathrm{Nu}_{\mathrm{CP}}$ flows. It is observed that $\mu(\mathrm{T})$ has a major influence on skin friction $\mathrm{C}_{\mathrm{f}}$, Darcy friction factor $\mathrm{f}_{\mathrm{D}}$ and the pressure with VP flows. The $C_{f}$ and $f_{D}$ are not affected by $C_{p}(T), \rho(T)$ and $k(T)$ flows.

In the Case 1 study, an increase in pipe radius results in; a decrease of $\mathrm{Nu}$ with $\mathrm{Nu}_{\mathrm{VP}}>\mathrm{Nu}_{\mathrm{CP}}$ and, lower values of $\mathrm{C}_{\mathrm{f}}$ and $\mathrm{f}_{\mathrm{D}}$ at pipe exit with VP as compared to $\mathrm{CP}$ flow. 
In the Case 2 simulations, an increase in inlet velocities gives; an increase in $\mathrm{Nu}$ with $\mathrm{Nu}_{\mathrm{VP}}>\mathrm{Nu}_{\mathrm{CP}}$ and, $\mathrm{C}_{\mathrm{f}}$ and $\mathrm{f}_{\mathrm{D}}$ show lower values at pipe exit with $\mathrm{VP}$ as compared to $\mathrm{CP}$ flows. The pressure drop $\Delta \mathrm{p}$ increases with an increase in inlet velocities showing lower values with VP as compared to $\mathrm{CP}$.

In the last Case study 3, an increase in constant wall flux $\mathrm{q}_{\mathrm{w}}$ results in; an increase of $\mathrm{Nu}$ with $\mathrm{Nu}_{\mathrm{VP}}>\mathrm{Nu}_{\mathrm{CP}}$ and, $\mathrm{C}_{\mathrm{f}}$ and $\mathrm{f}_{\mathrm{D}}$ show lower values at pipe exit with VP as compared to CP flows. An increase in heat flux results in a decrease of pressure drop $\Delta \mathrm{p}$ along pipe length with lower values of $\Delta \mathrm{p}$ with VP as compared to $\mathrm{CP}$.

The correlation between Nusselt number $\mathrm{Nu}$ and Reynolds number $\operatorname{Re}_{\infty}$ shows that $\mathrm{Nu}$ increases with an increase in $\mathrm{Re}_{\infty}$ for an increase in radii and inlet velocities, and $\mathrm{Nu}$ with VP shows higher values as compared to $\mathrm{CP}$. The $\mathrm{Nu}$ has negligible effect with an increase in heat flux and $\mathrm{Nu}$ shows higher values with VP as compared to CP.

\section{Nomenclature}

$\begin{array}{ll}\mathrm{C}_{\mathrm{f}} & : \text { Skin friction coefficient } \\ \mathrm{C}_{\mathrm{p}}(\mathrm{T}) & : \text { Temperature dependent specific heat capacity, } \mathrm{J} \mathrm{kg}^{-1} \mathrm{~K}^{-1} \\ \mathrm{D} & : \text { Pipe diameter, } \mathrm{m} \\ \mathrm{f}_{\mathrm{D}} & : \text { Darcy friction factor } \\ \mathrm{k}(\mathrm{T}) & : \text { Temperature dependent thermal conductivity, } \mathrm{Wm}^{-1} \mathrm{~K}^{-1} \\ \mathrm{~L} & : \text { Length of micro-tube, } \mathrm{m} \\ \Delta \mathrm{p} & : \text { pressure drop } \\ \mathrm{q}_{\mathrm{w}} & : \text { Constant wall heat flux, Wcm } \\ \mathrm{r}, \mathrm{z} & : \text { Radial and axial cylindrical coordinate, } \mathrm{m} \\ \mathrm{R} & : \text { Pipe radius, } \mathrm{m} \\ \mathrm{Re} & : \text { Reynolds number } \\ \mathrm{T}_{\mathrm{m}} & : \text { Bulk mean temperature, } \mathrm{K} \\ \mathrm{T}_{\mathrm{w}} & : \text { Wall temperature, } \mathrm{K} \\ \Delta \mathrm{T}=\left(\mathrm{T}_{\mathrm{w}}-\mathrm{T}_{\mathrm{m}}\right) \text { : Temperature difference, } \mathrm{K} \\ \mathrm{T}_{\mathrm{in}} & : \text { Inlet temperature, } \mathrm{K} \\ \mathrm{T}_{\text {out }} & : \text { Outlet temperature, } \mathrm{K} \\ \mathrm{u}_{\mathrm{in}} & : \text { Inlet velocity, } \mathrm{m} / \mathrm{s} \\ \mathrm{u}_{\mathrm{m}} & : \text { Bulk mean velocity, } \mathrm{m} / \mathrm{s} \\ \rho(\mathrm{T}) & : \text { Temperature dependent density, } \mathrm{Kg} / \mathrm{m}^{3} \\ \mu(\mathrm{T}) & : \text { Temperature dependent viscosity, } \mathrm{Nsm}^{-2}\end{array}$

\section{Subscripts}

$\begin{array}{ll}\mathrm{CP} & : \text { Constant properties } \\ \mathrm{VP} & : \text { Variable properties } \\ \mathrm{m} & : \text { Mean value } \\ \mathrm{w} & : \text { Wall } \\ \text { in } & : \text { Inlet } \\ \mathrm{e} & : \text { Exit }\end{array}$




\section{Acknowledgments}

The authors would like to thank the dean of King Abdul Aziz University, Jeddah for providing necessary facilities to carry out the research. The simulations in this work were performed at High Performance Computing Center (Aziz Supercomputer) (http://hpc.kau.edu.sa).

\section{References}

Asadi, M., Xie, G. and Sunden, B., 2014. A review of heat transfer and pressure drop characteristics of single and two-phase microchannels. International Journal of Heat and Mass Transfer, 79, pp.34-53.

Bergman, T. L. and Incropera, F. P., 2011. Fundamentals of Heat and Mass Transfer. John Wiley and Sons.

Dirker, J., Meyer, J. P. and Garach, D. V., 2014. Inlet flow effects in micro-channels in the laminar and transitional regimes on single-phase heat transfer coefficients and friction factors. International Journal of Heat and Mass Transfer, 77, pp.612626.

Dixit, T. and Ghosh, I., 2015. Review of micro-and mini-channel heat sinks and heat exchangers for single phase fluids. Renewable and Sustainable Energy Reviews, 41, pp.1298-1311.

Grigull, U. and Tratz, H., 1965. Thermischer einlauf in ausgebildeter laminarer rohrströmung [Thermal Inlet in Formed Laminar Tube Flow]. International Journal of Heat and Mass Transfer, 8(5), pp.669-678.

Gulhane, N. P. and Mahulikar, S. P., 2010. Numerical study of compressible convective heat transfer with variations in all fluid properties. International Journal of Thermal Sciences, 49(5), pp.786-796.

Gulhane, N. P. and Mahulikar, S. P., 2011. Numerical study of microconvective water-flow characteristics with variations in properties. Nanoscale and Microscale Thermophysical Engineering, 15(1), pp.28-47.

Herwig, H. and Mahulikar, S. P., 2006. Variable property effects in single-phase incompressible flows through microchannels. International Journal of Thermal Sciences, 45(10), pp.977-981.

Hetsroni, G., Mosyak, A., Pogrebnyak, E. and Yarin, L.P.. 2005a. Fluid flow in microchannels. International Journal of Heat and Mass Transfer, 48(10) pp.19821998.

Hetsroni, G., Mosyak, A., Pogrebnyak, E. and Yarin, L.P., 2005b. Heat transfer in micro-channels: Comparison of experiments with theory and numerical results. International Journal of Heat and Mass Transfer, 48(25), pp.5580-5601.

Kohl, M. J., Abdel-Khalik, S. I., Jeter, S. M. and Sadowski, D. L., 2005. An experimental investigation of microchannel flow with internal pressure measurements. International Journal of Heat and Mass Transfer, 48(8) (2005), pp.1518-1533.

Liu, D. and Garimella, S. V., 2007. Flow boiling heat transfer in microchannels. Journal of Heat Transfer, 129(10), pp.1321-1332.

Mahmoud, M. M. and Karayiannis, T. G.. 2013. Heat transfer correlation for flow boiling in small to micro tubes. International Journal of Heat and Mass Transfer, 66 , pp.553-574. 
Molho, J. I., Adrian, R. J., Sharp, K. V. and Santiago. J. G., 2005. Liquid Flows in microchannels: Introduction and Fundamentals. CRC press.

Morini, G. L., 2004. Single-phase convective heat transfer in microchannels: a review of experimental results. International Journal of Thermal Sciences, 43(7), pp.631-651.

Muzychka, Y. S. and Yovanovich, M. M., 1998. Modeling friction factors in noncircular ducts for developing laminar flow. In 2nd AIAA Theoretical Fluid Mechanics Meeting, pp.15-18.

Ozalp, A. A., 2010. Combined effects of pipe diameter, Reynolds number and wall heat flux and on flow, heat transfer and second-law characteristics of laminartransitional micro-pipe flows. Entropy, 12(3), pp.445-472.

Patankar, S., 1980. Numerical heat transfer and fluid flow. CRC press.

Rohsenow, W. M., Hartnett, J. R. and Cho, Y. I., 1998. Handbook of Heat Transfer. $3^{\text {rd }}$ Edition, New York, McGraw-Hill.

Sobhan, C. B. and Garimella, S.V., 2001. A comparative analysis of studies on heat transfer and fluid flow in microchannels. Nanoscale and Microscale Thermophysical Engineering, 5(4), pp.293-311.

Steinke, M. E. and Kandlikar, S. G., 2005. Single-phase liquid friction factors in microchannels. In ASME $3^{\text {rd }}$ International Conference on Microchannels and Minichannels, Toronto, Canada, pp.291-302.

Tuckerman, D. B. and Pease, R. F. W., 1981. High-performance heat sinking for VLSI. IEEE Electron device letters. 2(5), pp.126-129.

Weilin, Q., Mala, G. M. and Dongqing, L., 2000. Pressure-driven water flows in trapezoidal silicon microchannels. International Journal of Heat and Mass Transfer, 43(3), pp. 353-364. 
